ISSN: 0213-2060

DOI: https://doi.org/10.14201/shhme20203812957

\title{
LOS INICIOS DE LA ARQUITECTURA RELIGIOSA EN AL-ANDALUS Y SU CONTEXTO ISLÁMICO
}

\author{
Early Religious Architecture in al-Andalus and its Islamic Context
}

\author{
Susana CALVO CAPILLA \\ Depto. de Historia del Arte. Facultad de Geografia e Historia. Universidad Complutense de Madrid. Cl Profesor \\ Aranguren, s/n. Ciudad Universitaria.E-28040 MADRID. C. e.: susana.calvo@ucm.es
}

Recibido: 2019-11-18

Revisado: 2020-03-23

Aceptado: 2020-05-04

RESUMEN: En este artículo se reflexiona sobre lo que hoy sabemos de los espacios religiosos durante el llamado «islam temprano». En el contexto de los últimos estudios sobre ese período y su realidad cultural y religiosa surgen unas preguntas básicas que, si bien no encuentran todavía respuesta segura, conviene plantearse. Asimismo, debemos revisar los paradigmas usados hasta ahora para abordar su análisis, asumiendo lo que los historiadores han definido como una larga fase de transición. Ante la escasez y ambigüedad de las fuentes escritas coetáneas, los monumentos y los restos materiales conservados se convierten en los principales y más fiables documentos históricos. Que se omita su mención en los textos no impide que aquellas obras existan ni que se pueda hacer una aproximación a las razones por las que se crearon. De la misma manera, es altamente significativa la ausencia de respaldo material a ciertas informaciones de los relatos, sobre todo si esa ausencia es generalizada geográficamente hablando. Por eso, cabe preguntarse ¿cómo y dónde rezaban las primeras comunidades islamizadas tanto en el Mediterráneo como en al-Andalus? ¿Sabemos lo que buscamos cuando hablamos de las primeras masäŷid o lugares de prosternación?

Palabras clave: Al-Andalus; Islam temprano; Mezquitas; Lugares de oración; Prácticas religiosas; Textos religiosos.

ABSTRACT: This article reflects on what we know today about religious spaces during the so-called "Early Islam». In the context of the latest studies about this period and its cultural and religious reality, there are some basic questions worth asking, though still with no sure answer. Likewise, we must review the paradigms used so far to approach their analysis, assuming what historians have defined as a long phase of transition. Faced with the scarcity and ambiguity of contemporary written sources, the monuments and material remains preserved become the main and most reliable historical documents. The lack of 
mentions in the texts does not mean those works do not exist or that we could not make an approximation of the reasons behind their creation. Similarly, the absence of material support for certain information in the stories is highly significant, especially if that absence is generalized, geographically speaking. Therefore, it is worth asking how and where did the first Islamized communities pray both in the Mediterranean and in al-Andalus? Do we know what we are looking for when we speak of the first masâŷid or places of prostration?

Keywords: Al-Andalus; Early Islam; Mosques; Places of worship; Religious practices; Religious texts.

SUMARIO: 0 Introducción. 1 Lo sucedido fuera de la Península. Bilād al-Šàm. Palestina y Siria. 1.1 Siria. 1.2 Norte de África: Magreb e Ifriqiya. 2 Al-Andalus. 3 Definición del texto canónico, del ritual religioso y del espacio de oración. 4 Conclusiones. 5 Referencias bibliográficas.

\section{INTRODUCCIÓN}

Resulta interesante volver ahora al tema de las primeras masāyid (literalmente, lugares de prosternación) erigidas en al-Andalus, porque, si bien son escasos los nuevos hallazgos materiales, el estudio del primer periodo del Islam (llamado Early Islam) se ha visto enriquecido con publicaciones sobre varios lugares del Mediterráneo islámico y sobre los inicios del islam. Todo ello permite tener una perspectiva más amplia y confirmar que lo sucedido en la Península no se alejó demasiado de lo ocurrido en otras áreas de la Dàr al-Islàm. La primera vez que abordamos su estudio fue en el año 2007 y cuatro años más tarde el trabajo fue actualizado y publicado en francés ${ }^{1}$. En el artículo de 2011 insistíamos en que el modelo de islamización urbana en la Península reproducía los patrones documentados en el área del próximo oriente (Mašriq) y que se imitaban igualmente las tradiciones escritas. Con bastante frecuencia las primeras mezquitas documentadas en el Maśriq se levantaron en espacios urbanos centrales, pero ni sobre el emplazamiento de las iglesias ni reutilizando el propio edificio cristiano. Lo habitual es que estas permanecieran abiertas al culto cristiano un cierto tiempo tras la llegada de la nueva doctrina: Palmira, Bosra, Tiberias, Gerasa o Jerusalén, por ejemplo. A menudo los creyentes improvisaron espacios de culto en ámbitos o edificios adyacentes al área comercial o política de la ciudad y, esporádicamente, a las iglesias. Nuestras conclusiones provisionales, entonces, sobre la inexistencia de pruebas materiales que confirmasen las tradiciones literarias referentes a destrucciones masivas de los «templos politeístas», a su transformación en mezquitas o a su uso compartido con los cristianos, se han visto confirmadas en otros lugares como Siria, Palestina y Norte de África.

1 Ambos artículos figuran en la bibliografía. Este artículo ha sido realizado en el marco del proyecto de investigación $\mathrm{I}+\mathrm{D}+\mathrm{i}$ «Retos investigación» del Ministerio de Ciencia, Innovación y Universidades, RTI2018-093880-B-I00, Al-Andalus, arte, ciencia y contextos en un Mediterráneo abierto. De Occidente a Egipto y Siria. Agradezco los comentarios de los evaluadores y de los doctores J. Martínez de Aguirre, J. C. Ruiz Souza y E. González Ferrín, porque me han permitido reflexionar y mejorar el texto. 
Los autores árabes que construyen el relato de la conquista de la Península, cuando tratan el tema de la religiosidad de los conquistadores, componen una narración aderezada con topoi edificantes y apologéticos, análogos a los orientales. Las tradiciones supuestamente históricas se adornan con leyendas y anécdotas que les permiten crear una serie de mitos fundacionales de gran trascendencia simbólica, como la construcción de la «Mezquita de los estandartes» de Algeciras o las primeras mezquitas aljamas de Zaragoza y Córdoba. Insisten, en general, en dos aspectos fundamentales: el primero es que las iglesias fueron destruidas sistemáticamente y que, en núcleos de cierta importancia, las mezquitas aljamas se levantaron sobre sus ruinas ${ }^{2}$. Sin embargo, los restos materiales y los hallazgos arqueológicos hasta ahora no han respaldado ese extremo. Multitud de iglesias permanecieron en uso hasta que fueron progresivamente abandonadas; siglos después, los cristianos restauraron aquellos edificios y los consagraron de nuevo. En la Península los casos de Zaragoza y Sevilla son asimismo ejemplos de esos procesos, dado que bajo los recintos de sus primitivas mezquitas aljamas (todas ellas del siglo ix) las excavaciones encontraron restos de edificios romanos y tardoantiguos, respectivamente ${ }^{3}$. Los musulmanes rompieron asimismo con la orientación de las estructuras previas (y por lo tanto del viario de la ciudad antigua) para dirigir sus quibla-s al eje situado entre el orto del sol en el solsticio de verano y el ocaso en el solsticio de invierno.

El segundo tema recurrente en los textos árabes que narran las conquistas (futūhāt) fue el de atribuir estas fundaciones a unos personajes de gran prestigio religioso como eran los täbiün, "Sucesores de los Compañeros del Profeta», al igual que en el norte de África se atribuyó el trazado de las primeras quibla-s, es decir, la orientación de las mezquitas, a los șahāba o "Compañeros del Profeta», los primeros transmisores de sus palabras (hadices) ${ }^{4}$. Su pretendida existencia y presencia en las conquistas permitía a los tradicionistas establecer una garantía, a posteriori, de la pureza religiosa de los conquistadores, de su comportamiento impecable en la distribución del botín y de la ortodoxia del proceso de islamización del territorio. Crearon así unos mitos fundacionales muy necesarios para consolidar, en el caso de al-Andalus, el poder omeya, un fenómeno paralelo a lo que había sucedido en Oriente y el Norte de Africa ${ }^{5}$. De la misma manera que Mūsā b. Nuṣayr en la Península Ibérica, según la tradición literaria el conquistador de Egipto, 'Amr b. al-Āṣ, y los ochenta șahāba que iban con él establecieron hacia 22H/643

2 Calvo Capilla, Susana. "Les premières mosquées et la transformation des sanctuaires wisigothiques (92H/711-170H/785)». Mélanges de la Casa de Velázquez, 2011, vol. 41, n.o 2, pp. 140-142.

3 Calvo Capilla, Susana. Las mezquitas de al-Andalus. Almería: Fundación Ibn Tufayl de Estudios Árabes, 2014, pp. 28-39.

Calvo Capilla, Las mezquitas, pp. 33-35. Marín, M. «Ṣaḥāba et tābi'ūn dans al-Andalus: histoire et légende». Studia Islamica, 1981, vol. 54, pp. 5-49, analiza sus biografías y muestra la dudosa veracidad de su ubicuidad.

5alvo Capilla, «Les premières mosquées», pp. 135-136. Esas primeras colecciones de noticias o tradiciones no fueron escritas por verdaderos historiadores sino por tradicionistas religiosos. Véanse los límites históricos y el carácter apologético de lo transmitido por la «tradition savante musulmane» sobre la etapa de formación del islam en RoBin, Ch. Julien. «L'Arabie à la veille de l'Islam dans l'ouvrage de Aziz al-Azmeh. The Emergence of Islam in Late Antiquity». Topoi, 2017, vol. 21, pp. 293-297. Noth, Albrecht. The Early Arabic Historical Tradition. A Source-Critical Study. Second ed. in collaboration with Lawrence I. Conrad. Princeton, NJ: Darwin Press, 1994. 
la orientación de la mezquita aljama de la capital, al-Fusțāto y supervisaron el reparto de los lotes de tierras. En Ifriqiya, 'Uqba b. Nāfi' fundó en 50H/670 Qayrawān y ordenó la construcción de su gran mezquita, en cuyo trazado participó él mismo y los șahăăba y täbi ún que le acompañaron, encargados también de difundir el islam en aquellas tierras ${ }^{6}$.

También se hicieron eco los textos del topos oriental sobre el uso compartido de lugares de oración por cristianos y musulmanes, que en el caso de Damasco fue la explicación de los tradicionistas a las contradicciones en los relatos que circulaban sobre la conquista de la ciudad. La arqueología no ha podido demostrar por ahora esa circunstancia ni en el Mašriq ni en el Magreb; sin embargo, ha constatado que tanto en las ciudades de Próximo Oriente como en el norte de Africa algunas de las mezquitas más antiguas conocidas se construyeron junto a las iglesias principales, y ambos edificios fueron usados para el culto de sus respectivas comunidades al mismo tiempo durante años. En un primer momento, cuando la población era mayoritariamente cristiana, las iglesias dominaban el paisaje urbano. Pasado el tiempo, a partir del siglo viII o más tarde, según las regiones, las conversiones al islam y el aumento de la población obligó a ampliar las mezquitas aljamas y estas se convirtieron en el foco visual y funcional de la vida urbana.

\section{Lo sucedido fuera de la Península. Bilād al-Šs̄a. Palestina y Siria}

Gideon Avni recogió en 2014, en su libro The Byzantine-Islamic Transition in Palestine, la abundante información disponible sobre el proceso de islamización de toda la región de Palestina, tanto de los grandes núcleos urbanos como de las áreas rurales y beduinas. Son numerosos los ejemplos de coexistencia de espacios de culto (iglesias, sinagogas y mezquitas) documentados durante el periodo del Islam temprano. Como ya habían apuntado los trabajos previos de Devreesse y Pentz ${ }^{8}$, la conclusión de Avni a partir de numerosos hallazgos arqueológicos es que la transformación de las sociedades locales en Palestina y Jordania entre los siglos vi y vII muestra un cuadro complejo, pero preciso, de la lenta y gradual transición, lo que entra en contradicción con el paradigma

6 Se indicará la fecha de la Hégira con H. Asimismo, usamos aquí para facilitr la lectura los términos de «musulmán» (sería más correcto en esta época mu’minūn, creyentes) o mezquita (por el más genérico masyid, lugar de prosternación). Véanse notas 29 y 30.

Guidetri, Mattia. In the Shadow of the Church: The Building of Mosques in Early Medieval Syria. Leiden: Brill, 2016, pp. 20-30. También el capítulo "The Mosques of the Literary Sources» de AnTun, Thallein. The Architectural Form of the Mosque in the Central Arab Lands, from the Hijra to the End of the Umayyad Period, 1/622-133/750. Oxford, BAR International Series 2790, 2016.

8 Decía Devreesse en 1940 sobre las excavaciones en Sbaïta-Shivta «Il semble se dégager de tout ceci que l'Islam n'a point été tout d'abord, pas plus dans le Négeb [sic] qu'ailleurs, le torrent dévastateur qu'on imagine parfois» («Le Christianisme dans le Sud palestinien». Revue des Sciences Religieuses, 1940, tome 20, fascicule 3-4, p. 250). Pentz, Peter. The Invisible Conquest: The Ontogenesis of Sixth and Seventh Century Syria. Copenhagen: National Museum of Denmark, 1992, analizó, desde el punto de vista económico, la lenta transformación de la región. Todos ellos insisten en la idea de transición dentro de un contexto tardoantiguo. 
previo de un hostil escenario de "humo y fuego» fruto de una conquista violenta seguida de un rápido cambio?

En el área estudiada por Avni, que incluye Palestina y Jordania, las mezquitas más antiguas encontradas en ciudades preislámicas, en asentamientos tipo quṣūr y ribàt (establecimientos de fundación islámica), así como en áreas rurales, han sido datadas no antes de la década final del siglo viI o principios del viII ${ }^{10}$. Los qușūr poseían mezquitas sencillas de planta cuadrangular con un mihrāb semicircular bastante profundo, a menudo separadas de la estructura palatina. Ejemplos conocidos son, entre otros, los conjuntos jordanos de Qasr Hallabat, Umm al-Walīd, al-Qastal (con el alminar circular más antiguo conocido) y Humayma, una fortaleza romana ocupada por un asentamiento cristiano con varias iglesias que fue abandonado y reutilizado como residencia en el Islam temprano a partir de 687-688 ${ }^{11}$. En el imponente ribāt de Qal'at al-Mina, de las mismas fechas, la mezquita estaba dentro del recinto ${ }^{12}$. El paso del cristianismo al islam en la región es complicado de detectar e incluso, según Avni, en muchos lugares no hubo islamización de verdad hasta época de los cruzados. Los casos de reutilización de un edificio de culto judío o cristiano son excepcionales y siempre ocurrieron una vez abandonado el espacio, como en Khirbet Susiya y Eshtamo'a, donde la mezquita se instaló tardíamente, en el siglo viII, en una sinagoga sin uso, lo que supone en este caso el único indicio material del cambio de la sociedad ${ }^{13}$.

En la zona del Negev se han hallado varias mezquitas de carácter rural o beduino dentro de variados asentamientos de época bizantina o del Islam temprano. Entre los grandes núcleos, uno de los más singulares es Sbaïta-Shivta, ciudad surgida en el siglo v, donde se levantó la mezquita en un espacio adyacente al baptisterio de una de sus tres iglesias, lo que da testimonio de la penetración del islam en la población local mayoritariamente cristiana y el uso simultáneo de la iglesia y la mezquita durante el periodo islámico inicial. El interior estaba decorado con inscripciones, una de carácter fundacional y otras coránicas, que permiten datar el uso del edificio desde el siglo viI hasta, al menos, $\mathrm{el}^{14}$. En otras poblaciones de menor tamaño, como Be'er Ora o Sede Boqer, las mezquitas son de pequeńas dimensiones y a cielo abierto (open-air mosque), con paredes que no tenían más de un metro de alto. La de Sede Boqer consiste en una sala de oración rectangular de $5 \times 12 \mathrm{~m}$, con un mihrāb semicircular en el muro sur y un patio cuadrado. Varias inscripciones árabes incisas en la roca madre sobre la que se asienta la

9 Avni, Gideon. The Byzantine-Islamic Transition in Palestine. An Archaeological Approach. Oxford: Oxford University Press, 2014, p. VII: «In contradiction of the harsh scenario of 'smoke and fire' that emphasizes a violent conquest followed by a rapid change, archaeological findings paint a much milder picture»; ver también «Conclusion», pp. 344-353.

10 Avni, The Byzantine-Islamic, p. 335. En su opinión, estos asentamientos de población musulmana estaban en cierta medida aislados del entorno; a su vez, las comunidades cristianas y judías mantuvieron su identidad cultural y religiosa y solo recibieron influencias del islam de manera esporádica.

11 Avni, The Byzantine-Islamic, pp. 225-227, 238.

12 Avni, The Byzantine-Islamic, pp. 242-243.

13 Avni, The Byzantine-Islamic, pp. 254-256.

14 Moor, Bilha. "Mosque and Church: Arabic inscriptions at Shivta in the Early Islamic Period». Jerusalem Studies in Arabic and Islam, 2013, vol. 40, pp. 73-141. Avni, The Byzantine-Islamic, pp. 264-266, 458-459. Devreesse, «Le Christianisme dans le Sud palestinien». 
mezquita permiten datar la construcción del edificio con posterioridad al año $782^{15}$. En casos como la mezquita a cielo abierto de Nahal 'Oded se ha documentado una curiosa sustitución del mihrāa por estelas, lo que para Avni podría indicar la pervivencia de las prácticas preislámicas de culto y la gradual transición del culto pagano a las primeras prácticas islámicas ${ }^{16}$. Asimismo, el hecho de que muchos de los asentamientos estudiados fueran de época preislámica (y pagana) y que sus mezquitas a cielo abierto daten del siglo viII probaría que el proceso de transformación de la religión y el culto se produjo muy lentamente en la región ${ }^{17}$. En Rahat, al norte del Negev, apareció en 2019 otra mezquita a cielo abierto con un nicho semicircular conformado por un sillarejo perfectamente labrado en curva. Se añade al catálogo recogido por Avni en el libro. Él mismo se inclina por datar este ejemplo en las mismas fechas que todas las demás, en los años finales del siglo VII y comienzos del viII, no hay razones para pensar que fueran más tempranas ${ }^{18}$.

En lo que se refiere a grandes ciudades, en Tiberias se constata igualmente la pervivencia de las iglesias, abiertas al culto al menos hasta el siglo $\mathrm{x}$, y la construcción de una mezquita aljama junto al templo principal, de manera que ambos edificios funcionaron simultáneamente. En un principio, la iglesia dominaba el paisaje urbano del centro de la ciudad, un centro "multireligioso" dice Cytryn-Silverman ${ }^{19}$. Cuando la mezquita se amplía al final del periodo omeya, siguiendo el modelo de la mezquita de Damasco según esta autora, esta superaría en tamaño y altura a la iglesia. Es más, el alminar debió situarse justo en la calle que separaba ambos lugares de culto.

En Jerusalén, el testimonio del obispo Arculfo, que supuestamente visitó Damasco y Jerusalén (conquistadas en 14H/635 y 17H/638, respectivamente) hacia el 670, ha servido para explicar la temprana presencia de un lugar de oración en la explanada del antiguo Templo de Jerusalén, el ḥaram al-šarîf, en el área donde después se levantó la mezquita de al-Aqsa a inicios del viII. No obstante, bajo dicha mezquita la arqueología no encontró restos claramente datables en el siglo viI. Otras fuentes referentes a Jerusalén aluden a un primer oratorio instalado por el califa ' $U \operatorname{mar}(\mathrm{m} .23 \mathrm{H} / 644)$ coincidiendo con la conquista de la ciudad, o bien al del primer califa omeya Mu'āwìya $(41 \mathrm{H} / 661-60 \mathrm{H} / 680)$, que celebró su bay'a allí. En muchos casos la historiografía ha asumido precipitadamente que aquellos primeros supuestos oratorios de Jerusalén y de Damasco, instalado este último en el témenos romano donde estaba la iglesia de San Juan Bautista, tuvieron ya forma de sala hipóstila, el modelo canónico documentado en las tempranas Kūfa, Wāsiț, Boṣrā,

15 Avni, The Byzantine-Islamic, pp. 268 y 284, respectivamente.

16 Avni, The Byzantine-Islamic, pp. 271, 284-285

17 Avni, The Byzantine-Islamic, pp. 458-459.

18 https://www.haaretz.com/israel-news/.premium-one-of-the-earliest-rural-mosques-in-the-worldfound-in-israel-1.7539392 (consultado: 19/08/2019).

19 Cytryn-Silverman, Katia. «Tiberias' Houses of Prayer in Context». En Patrich, Joseph; PelegBarkat, Orit y Ben Yosef, Erez (eds.). Arise, walk through the land. Studies in the Archaeology and History of the Land of Israel in Memory of Yizhar Hirschfeld on the Tenth Anniversary of his Demise. Jerusalem: The Israel Exploration Society, 2016, pp. 235-248; ÍDEm. «The Umayyad mosque of Tiberias». Muqarnas, 2009, vol. 26, pp. 37-61. Véase el plano y los materiales encontrados en ÍDEm, Tibériade au début de l'ère islamique, 2009-2013. https://maxvanberchem.org/fr/activites-scientifiques/projets/archeologie/11-archeologie/36-city-centreof-early-islamic-tiberias (consulta: 15/08/2019). GuideTti, In the Shadow, pp. 63-64. 
al-Aqșā de Jerusalén o Fusțāt ${ }^{20}$. Aunque fueran construcciones poco sólidas, con materiales reutilizados y cubierta de madera, se asume que dicho modelo ya había surgido a mediados del siglo viI en época de 'Umar y Mu'āwìya.

El debate sobre la primera «mezquita» de Jerusalén sigue de actualidad gracias a varias publicaciones que se interrogan sobre el significado de los textos y de los escasos restos del siglo vir hallados, así como sobre la Cúpula de la Roca (fechada por una inscripción en $72 \mathrm{H} / 691-692)^{21}$. Del exhaustivo repaso de las fuentes conocidas, tanto árabes como no árabes, que ha hecho Lawrence Nees parece concluirse que no tenemos evidencias para confirmar la construcción en el siglo vil de una mezquita (entendida como edificio de varias naves, orientación precisa y elementos identificativos) ni de su localización exacta dentro del haram al-šarîf ${ }^{22}$. Nees ha planteado la hipótesis de que aquel primer oratorio islámico en Jerusalén fuera todo el recinto a cielo abierto del haram al-šarîf una especie de musalla (algunas fuentes así parecen sugerirlo y resultaría plausible) y que, en una propuesta más arriesgada, la llamada qubbat al-silsila, o Cúpula de la Cadena, pudo ser construida en época de Mu'āwìya ibn Ảbī Sufyān (661-680) como su minbar o macsura. En estos casos (pensamos asimismo en Córdoba) el análisis de los monumentos y sus materiales proporciona más información que las fuentes escritas, sobre todo si no son contemporáneas. Las propias obras son un documento histórico.

Otros autores como Beatrice St. Laurent e Isam Awwad plantearon en 2014 una teoría menos convincente que consiste en identificar parte de unas estructuras antiguas del ángulo sureste del Haram conocidas como Istablat Suleiman, establos de Solomon, como restos de la primera mezquita de Jerusalén vista por Arculfo (levantada por 'Umar o Mu'āwìya), siendo el muro sur del recinto el usado como quibla ${ }^{23}$. Di Cesare, por su parte, propone reinterpretar los restos arqueológicos más antiguos hallados por Hamilton (1938-1942) bajo la mezquita de al-Aqșa (Aqșa I) como un primer oratorio construido por Mu'āwìya, pero orientado al este y no al sur, con naves paralelas y no perpendiculares a la quibla y carente de mihrā $b^{24}$. De ello extrae la autora que la adopción de la nueva orientación hacia el Sur se produjo en paralelo a la introducción en la quibla del mị̂rāb cóncavo, ya en época de al-Walìd (86-96H/705-715) 25 .

20 Antun, The Architectural Form, pp. 6-49.

21 Una de las últimas aportaciones es Milwright, Marcus. The Dome of the Rock and Its Umayyad Mosaic Inscriptions. Edinburgh: Edinburgh University Press, 2016.

22 Nees, Lawrence. Perspectives on Early Islamic Art in Jerusalem. Leiden: Brill, 2016, caps. 2 y 3 dedicados al análisis de las fuentes escritas (pp. 5-57) y pp. 58-99.

23 Los trabajos de limpieza y reforma en el ángulo sureste del recinto comenzaron hacia 1996. Sobre ellos, véase Seligman, Jon. «Solomon's Stables, the Temple Mount, Jerusalem: The Events Concerning the Destruction of Antiquities 1999-2001». Atigot, 2007, vol. 56, pp. 33-53.

24 Di Cesare, Michelina. «A qibla mušarriqa for the First al-Aqșà Mosque? A New Stratigraphic, Planimetric, and Chronological Reading of Hamilton's Excavation, and Some Considerations on the Introduction of the Concave mihrāb». Annali dell'Università degli Studi di Napoli "L'Orientale". Sezione Orientale, 2017, vol. 77, n. ${ }^{\circ}$ 1-2, pp. 66-96. Para Hamilton Aqsa I era la etapa de al-Walid. Véase también NeEs, Perspectives, pp. 13-16.

25 Di Cesare, "A qibla mušarriqa», pp. 89-90. 


\subsection{Siria}

En el libro publicado en 2016 reconoce Mattia Guidetti la dificultad de identificar los oratorios de la etapa más temprana del islam. Muy pocas fuentes escritas (algunas no árabes y raramente coetáneas) hablan de las actividades constructivas de los conquistadores. En general, la historia de muchos de los edificios que terminaron integrando el paisaje monumental sagrado del islam, sustituyendo al cristiano, se compuso a posteriori, en el momento en que era necesario construir unos mitos fundacionales de esas construcciones para anclar la tradición islámica al territorio ${ }^{26}$. Constata Guidetti el mismo fenómeno que habíamos documentado en al-Andalus, a saber, que los tradicionistas inventan un escenario completamente diferente del que ha revelado la arqueología, una versión partidaria donde las iglesias fueron remplazadas por mezquitas, fueron destruidas o islamizadas ${ }^{27}$.

Varios de aquellos primeros espacios de oración islámicos se levantaron junto a las iglesias o "en diálogo» con ellas, de manera que ambos edificios fueron usados de forma simultánea durante mucho tiempo, algo que quizá fue interpretado por las fuentes posteriores como espacios compartidos. Los autores que relatan las conquistas aluden de manera contradictoria al reparto de propiedades y al uso compartido de las iglesias por ambas comunidades religiosas, una fórmula que no ha podido demostrarse en Damasco, Diyarbakir, Homs ni Alepo ${ }^{28}$. Bashear reunió las noticias donde los tradicionistas atribuían a los primeros Califas y a los Compañeros, Sucesores o religiosos de prestigio dirigir sus rezos hacia el Este en santuarios de especial significado para la comunidad cristiana de Tierra Santa recién conquistada. No eran casos de iglesias compartidas ni convertidas en mezquitas, sino hechos ocasionales y personajes excepcionales a los que se concedía un especial significado ${ }^{29}$. No parece errado considerar que los relatos sobre la atracción que algunas iglesias tenían para los primeros creyentes (muiminün) fueron una elaboración literaria e historiográfica posterior en varios siglos a la conquista, cuyo fin pudo ser ensalzar su triunfo (¿o superación?) sobre el cristianismo ${ }^{30}$. De cualquier forma,

26 Guidetti, In the Shadow, pp. 20-30, 68 y 174; Bashear, Suliman. «Qibla musharriqa and Early Muslim Prayer in Churches». The Muslim World, 1991, vol. LXXXI, n. ${ }^{\circ} 2-3$, pp. 267-282.

27 GuidetTi, In the Shadow, cap. 2, pp. 13-35, especialmente p. 30: Hama, Jerusalén, Damasco, etc. Calvo Capilla, Susana. «Las primeras mezquitas de al-Andalus a través de las fuentes árabes (92/711170/785)». Al-Qantara, 2007, vol. 28, n. ${ }^{\circ}$ 1, pp. 143-179; e ÍDEM, «Les premières mosquées».

28 Calvo Capilla, Susana. «Analogies entre les grandes mosquées de Damas et Cordoue: mythe ou réalité?». En Borrut, Antoine у Совв, Paul M. (eds.). Umayyad legacies: medieval memories from Syria to Spain. Leiden: Brill, 2010, pp. 281-311 e ÍDEM, «Les premières mosquées», pp. 152-154; GuIDETTI, In the Shadow, pp. 37-41.

${ }_{29}$ Sobre el significado de los masâyid en pasajes del Corán, como en 72:18-19, podría entenderse como lugares de oración en general incluidos los politeístas; véase Dye, Guillaume y ReYNoLDs, Gabriel Said. «Sourate 72. al-Jinn (les djinns)». En Dye, Guillaume y Amir-Moezzi, Mohammad (dir.). Le Coran des historiens: Volume 2b. Paris: Éditions du Cerf, 2019, p. 1864.

30 Donner, Fred. Muhammad and the believers. At the origins of Islam. Cambridge: Cambridge University Press, 2010, p. 115. Este autor habla de «creyentes» en los orígenes del islam, un movimiento de reforma religiosa dentro del monoteísmo iniciado por el profeta Muhammad. El movimiento de los creyentes incluía a cristianos y judíos justos en sus primeros años, que acordaron vivir rectamente en obediencia a su ley revelada. La conciencia de que constituían una comunidad religiosa separada, distinta de los cristianos y los 
este tipo de acciones fue pronto incluido por los exégetas entre las prácticas reprobables porque implicaban la imitación de los idólatras y el rezo hacia una orientación errónea. De hecho, la orientación fue un asunto recurrente en la literatura polémica de cristianos y musulmanes, como volveremos a ver más adelante ${ }^{31}$. Guidetti, por su parte, concluye que dichas acciones, si existieron, debieron ser efímeras y limitadas a los primeros tiempos de la conquista, dado que no han dejado rastro reconocible ${ }^{32}$.

La catedral y la mezquita fueron edificios adyacentes o contiguos en ciudades como Alepo, Homs, Mosul, Mardin, Diyarbakir. En algunos casos se llegó a confiscar una parte del recinto o área que rodeaba a la iglesia, como fue el caso de al-Rușāfa, donde la mezquita aljama omeya se adosó al atrio norte del conjunto de la basílica bizantina de San Sergio $^{33}$ (Fig. 1). En al-Bajra', también en la actual Siria, una fortaleza bizantina reocupada en época omeya, Genequand identificó como mezquita una sala hipóstila adosada al muro norte de la iglesia ${ }^{34}$; y, por último, en Amman la mezquita mayor fue construida en época omeya junto a la catedral, ambas desaparecidas, pero aún visibles a finales del siglo $\mathrm{XIX}^{35}$. ¿Fue este mismo el caso de la primera mezquita aljama de Córdoba? ¿Se levantó en un espacio adyacente a la basílica, en el área episcopal de la ciudad? Como ya analizamos en su momento, las tradiciones escritas con anterioridad a la llegada del mito de la partición y de la expropiación por parte de Abd al-Rahman I de la basílica de San Vicente de Córdoba, hablan de manera ambigua sobre la cercanía de aquella iglesia al alcázar y a un primer lugar de oración de los árabes, lo que fue interpretado de diversas formas ${ }^{36}$.

judíos, surgió un siglo después, cuando asumen que el Corán es la revelación final del Dios Único, superación del Evangelio y la Torá, y Muhammad es el profeta.

31 Bashear, "Qibla musharriqa», p. 268; Calvo CaPilla, Susana. "Justicia, misericordia y cristianismo: una relectura de las inscripciones coránicas de la Mezquita de Córdoba en el siglo x». Al-Qantara, 2010, vol. 31, n. ${ }^{\circ}$ 1, pp. 149-187; Í DEM, Las mezquitas, pp. 49-50.

32 GuidetTi, In the Shadow, p. 68. La teoría de Avner sobre el uso compartido por cristianos y musulmanes de la iglesia de la Kathisma, cerca de Jerusalén, no está confirmada ni ha sido aceptada por todos los investigadores; la autora defiende la construcción de un mihrrab en torno al año 700 , si bien no está atestiguado que tras ello el santuario siguiera siendo usado por los cristianos (Grabar, Oleg. The Dome of the Rock. Cambridge, MA: Harvard University Press, 2006, pp. 89-119, GuidetTi, In the Shadow, pp. 68-69). También considera este edificio un posible modelo de la Cúpula de la Roca Avner, Rina. «The Dome of the Rock in light of the development of concentric Martyria in Jerusalem: Architecture and Architectural Iconography». Muqarnas, 2010, vol. 27, pp. 31-50.

33 SACK, Dorothy. Resafa IV, Die Grosse Moschee von Resafa-Rusafat Hisam. Mainz: Deutsches Archäologisches Institut, 1996.

34 Genequand, Denis. «Al-Bakhra' (Avatha), from the Tetrarchic fort to the Umayyad castle». Levant, 2004, vol. 36, pp. 235-236. No obstante, no se halló evidencia del mihrab.

35 GuidetTI, In the Shadow, cap. 3, pp. 36-70.

36 Estudiado por M. Ocaña Jiménez, ref. en Calvo Capilla, «Les premières mosquées», p. 152. Véase un resumen de las lecturas hechas hasta la fecha de los restos arqueólogicos en Toral-NieHoff, Isabel y León Muñoz, Alberto. «Ornament of the World: Urban Change in Early Islamic Qurțuba». En Panzram, Sabine (ed.). The Power of Cities. The Iberian Peninsula from Late Antiquity to the Early Modern Period. Leiden: Brill, 2019, pp. 114-115. 

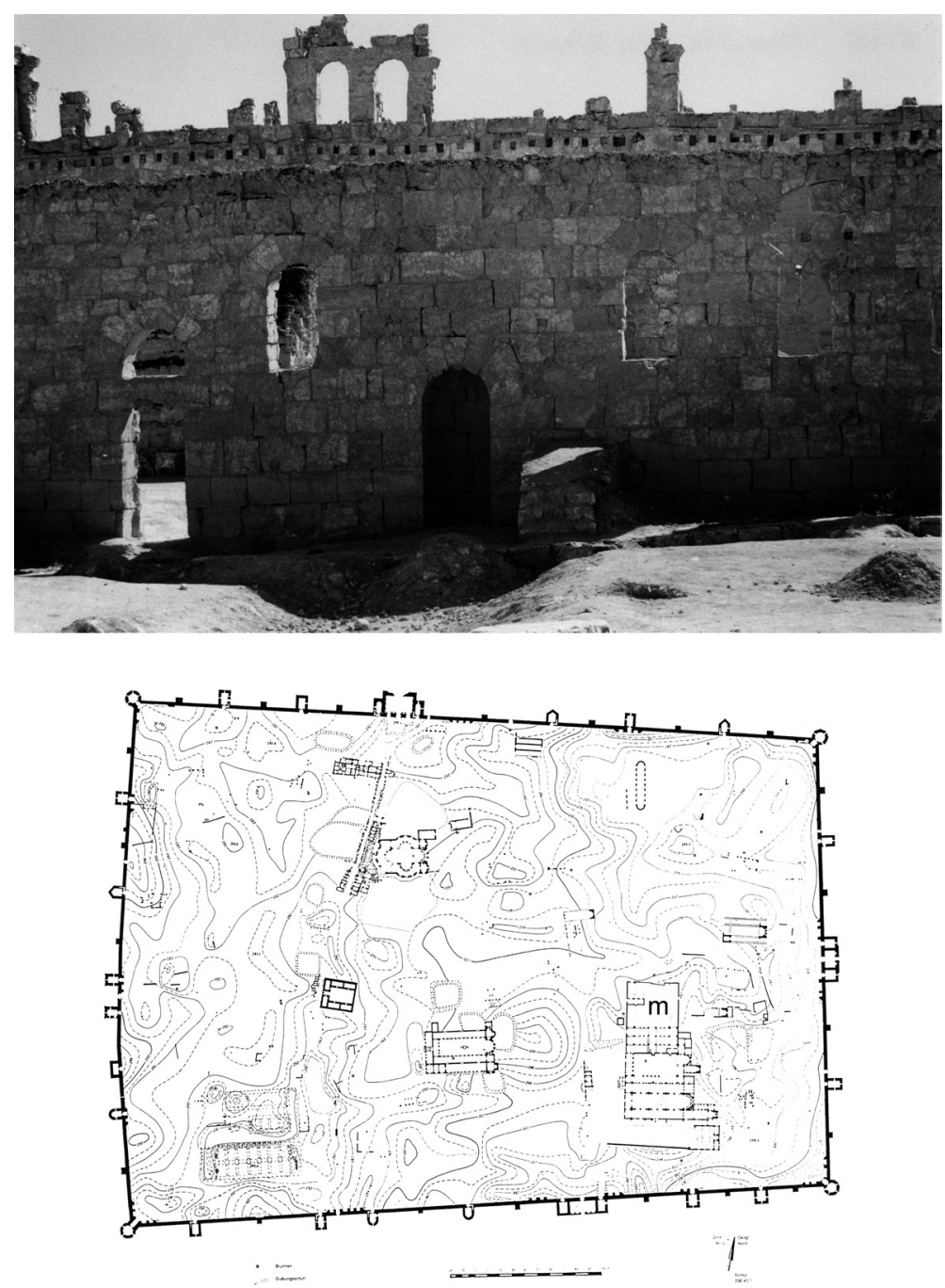

Figura 1. Mezquita de Rusafa (Siria). Quibla (foto de la autora) y planta de Sack, Resafa IV.

No obstante, no hubo un modelo único y, al igual que sucedió en Jerusalén, en varias ciudades se eligió para levantar el oratorio un sector de la ciudad diferente al centro religioso cristiano (bizantino), caso de Boṣrā, Gerasa o Palmira, en las que se documentan las primeras fases de ocupación desde finales del siglo viI. En los tres sitios se levantó la mezquita en época omeya reutilizando edificios abandonados de la ciudad tardoantigua cercanos al centro urbano (al tetrakionion romano en Gerasa (Fig. 2) y Palmira; en una 
de las vías principales en Boșrā) y al área comercial, revitalizada por los Marwāníes ${ }^{37}$. En esas ciudades las iglesias se mantuvieron abiertas al culto ${ }^{38}$. Aquella localización junto a los mercados se repitió en 'Anŷar (Líbano), Amman y en Ayla-Aqaba (Jordania), ciudades omeyas de nueva planta que seguían el modelo urbano clásico.

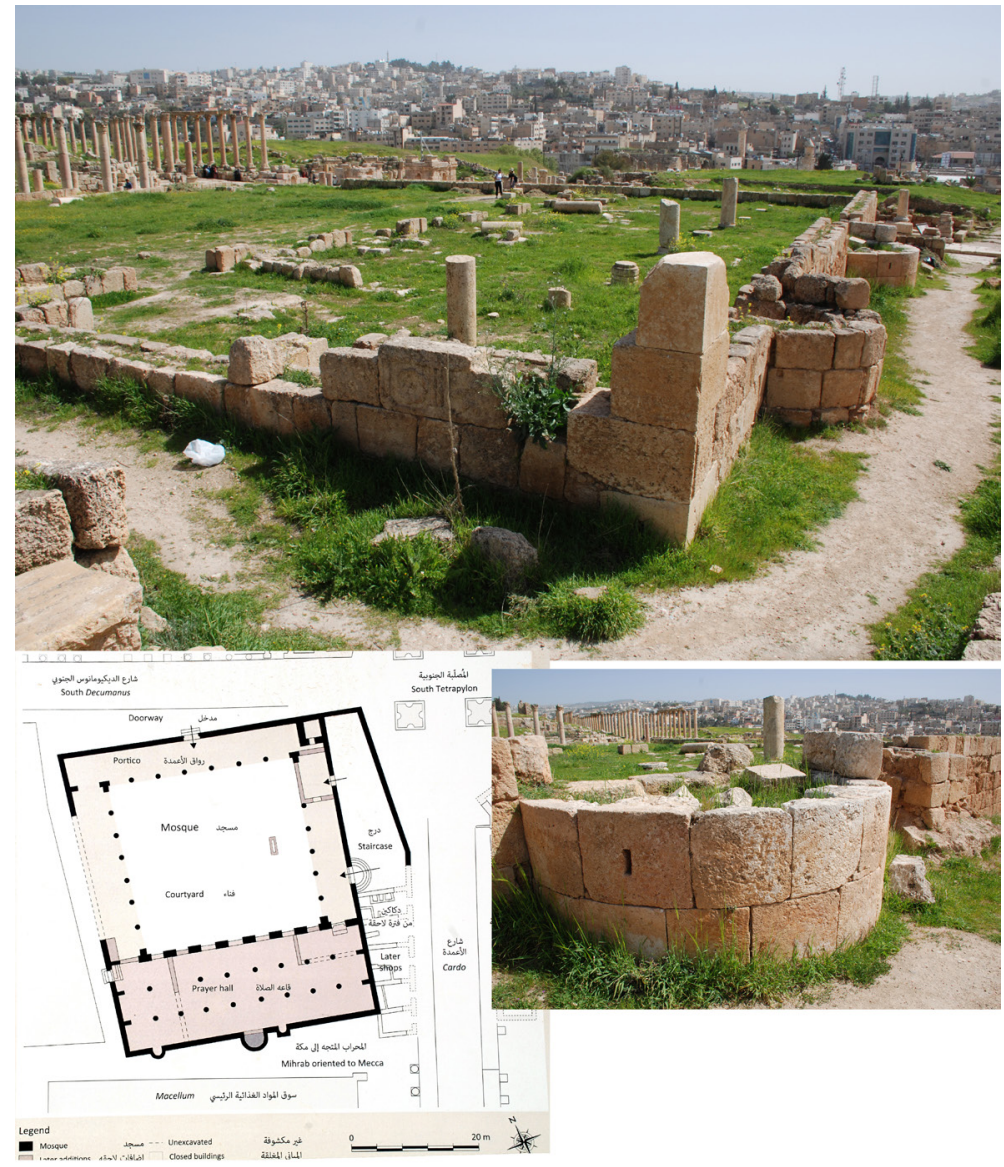

Figura 2. Mezquita de Gerasa (Jordania). Fotos de J. C. Ruiz Souza.

Retomando las palabras de Walmsley y Damgaard, en las áreas urbanas de esta región el control (y la recaudación de impuestos) era ejercido por la iglesia desde finales

37 Guidetti, In the Shadow, pp. 63-64, 103; Calvo Capilla, «Les premières mosquées», pp. 138139; Genequand, Denis. «An Early Islamic Mosque in Palmyra. Une mosquée du début de l'époque islamique à Palmyre». Levant, 2008, vol. 40, pp. 3-15.

38 Rattenborg, Rune y Blanke, Louise. "Jarash in the Islamic Ages (c. 700-1200 CE): a critical

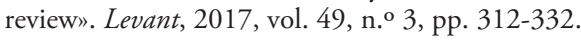


del siglo vi hasta que comenzó a ser sustituido progresivamente por una nueva administración musulmana tras las reformas de 'Abd al-Malik (r. 65-86H/685-705). A partir de ese momento y hasta el año 750 hubo una frenética actividad constructiva que proveyó de mezquitas aljamas a los centros provinciales, al tiempo que disminuía la actividad y el número de iglesias en uso, con el consiguiente debilitamiento del poder de las autoridades eclesiásticas ${ }^{39}$.

\subsection{Norte de África: Magreb e Ifriqiya}

En la investigación sobre el paso de la Antigüedad Tardía al Islam en el norte de África, fundamentalmente en Ifriqiya (actual Túnez), el trabajo de Pentz de 2002 fue un jalón importante para empezar a cuestionar el paradigma tradicional del cambio traumático de las ciudades antiguas y bizantinas tras la llegada del islam. Recientemente, diversas aportaciones de carácter arqueológico han incidido en la tesis de la continuidad (Baratte, Mahfoudh, o Fenwick, entre otros). Aunque todavía queda mucho por hacer en el terreno de los lugares de oración (sobre todo en la zona más occidental, en el actual Marruecos), se vislumbra un escenario similar al Levante. Según Fenwick (2018) las iglesias continuaron siendo el elemento dominante del paisaje urbano durante el siglo viII. Algunas iglesias permanecieron abiertas durante siglos después de la conquista, como en Sbeïtla, algunas de cuyas basílicas continuaron en uso hasta los siglos X-XI; otras pasaron a funciones seculares como prensas de aceite, mercado, etc., o bien fueron desmanteladas para usar los materiales. Se ha documentado incluso la construcción de nuevas iglesias en Qayrawan en el siglo viII.

En cuanto a las iglesias transformadas en mezquitas, las tradiciones histórico-religiosas mencionan algunos ejemplos que, o bien no se han podido confirmar con indicios materiales (es el caso de la mezquita aljama de Túnez, al-Zaytuna), o bien la transformación sucedió muchos siglos después (como la mezquita aljama de Le Kef, antigua Sicca Veneria $)^{40}$. Tampoco se ha podido documentar ningún oratorio levantado en los momentos iniciales del periodo islámico, aunque sí más tarde en ciudadelas bizantinas (como Belalis Maior, Bagaï o Tobna). Son interesantes el edificio llamado «de las columnas» de Haïdra, que se sospecha pudo ser una mezquita ${ }^{41}$, y la mezquita construida en la fortaleza bizantina de Aïn Tebournouk, que, si bien data del siglo xviı, pudo erigirse sobre un oratorio del siglo IX o $\mathrm{X}^{42}$. La mayoría de dichas mezquitas data de época aglabí (siglo

39 Walmsley, Alan y DamgaArd, Kristoffer. "The Umayyad congregational mosque of Jarash in Jordan and its relationship to early mosques». Antiquity, 2005, vol. 79, n. o 304, pp. 362-363.

40 Mahfoudh, Faouzi. "Commerce de marbre et remploi dans les monuments de l'Ifriqiya médiévale». En Altekamp, Stefan; Marcks-Jacobs, Carmen y Seiler, Peter (eds.). Perspektiven der Spolienforschung 2. Zentren und Konjunkturen der Spoliierung. Berlin: Edition Topoi, 2017, pp. 15-42.

41 Baratte, François. «Recherches franco-tunisiennes sur la citadelle byzantine d'Ammaedara (Haïdra)». Comptes rendus des séances de l'Académie des Inscriptions et Belles-Lettres, 1996, vol. 140, n. ${ }^{\circ}$ 1, p. 153.

42 Ghalia, Taher y Mahfoudh, Faouzi. "Aïn Tebournouk-Tubernuc et sa région de l'Antiquité tardive au Moyen Âge». Mélanges de l'École Française de Rome. Antiquité, 2003, vol. 115, n.o 2, pp. 794-795. La suposición viene motivada porque la estructura es semejante a las mezquitas de nueve tramos de Qayrawan y Susa, aunque aún no se ha excavado. También Baratte, François. "Les villes du nord de l'Afrique entre 
IX), incluidas las aljamas de las capitales, y, de momento, no hay registros arqueológicos anteriores. Según Fenwick, «inicialmente parece posible que las mezquitas estuvieran en las ciudadelas o fortalezas de las guarniciones de tropas musulmanas, y en las capitales de provincias donde se supone que vivirían los recién llegados» ${ }^{43}$.

En Yebel Nefūsa (Libia), Virginie Prevost ha estudiado algunos casos interesantes de tardías conversiones o sustituciones de iglesias bizantinas. Hasta la desaparición de las comunidades cristianas con el progresivo avance de la islamización de la región (a partir de 643-644), las iglesias se mantuvieron abiertas. Solo después, cuando aquellas fueron abandonadas, los musulmanes (ibadies en la región) reocuparon los lugares, unas veces reutilizando el edificio cristiano y otras construyendo la mezquita en su solar. Según Prevost, lo hacían "por apego a un lugar sagrado que antes fue venerado por sus antepasados». De hecho, ciertas mezquitas sin resto alguno de la iglesia, portan un nombre con reminiscencias cristianas o reciben el apelativo de «apostólicas» (en las fuentes del siglo $\mathrm{XVI}$ ). Lo que nos interesa retener es que en esta región del norte de África las conversiones no se produjeron en ningún caso en el periodo de transición sino mucho más tarde ${ }^{44}$.

\section{Al-Andalus}

Desde la publicación de los dos artículos mencionados, donde insistíamos en la lenta transición que determina el siglo viII en la Península ${ }^{45}$, son escasos los avances en el conocimiento de los oratorios andalusíes de ese periodo, a excepción de Córdoba.

En Recópolis (Guadalajara), la ciudad fundada por Leovigildo en el año 578, los estudios geomagnéticos recientes han mostrado la gran extensión de la ciudad regia hispanogoda y han permitido identificar un gran edificio con una orientación diferente al resto de las estructuras de la ciudad, incluidas el aula palatina y la iglesia. El edificio rectangular, de unos $20 \times 40 \mathrm{~m}$, orienta uno de sus lados largos al sudeste. Dado que hay evidencias arqueológicas en las estructuras ya excavadas de la temprana reutilización por los conquistadores, los autores del estudio proponen que dicho edificio podría ser una

Antiquité tardive et conquête arabe. Historiographie récente et nouvelles perspectives». En Panzram, Sabine y Callegarin, Laurent (coords.). Entre civitas y madina. El mundo de las ciudades en la Península Ibérica y en el norte de África (siglos IV-IX). Madrid: Casa de Velázquez, 2018, pp. 198-99.

43 Fenwick, Corisande. «Early Medieval Urbanism in Ifriqiya and the Emergence of the Islamic City». En Panzram, Sabine y Callegarin, Laurent (coords.). Entre civitas y madina. El mundo de las ciudades en la Península Ibérica y en el norte de África (siglos IV-IX). Madrid: Casa de Velázquez, 2018, pp. 218-219: textualmente dice «incoming Arabs».

$44 \quad$ Prevost, Virginie. «Des églises byzantines converties à l'islam? Quelques mosquées ibadites du djebel Nafûsa (Libye)». Revue de l'Histoire des Religions, 2012, vol. 3, pp. 325-347. Mezquita apostólica o masŷid al-ḥawāriyyīn.

45 Aquí incluimos también Portugal, donde se han hallado en los últimos años estructuras religiosas (Castelo Velho de Alcoutim y Montinho das Laranjeiras, en el Algarve, por ejemplo), pero ninguna de la etapa inicial del siglo viII o inicios del Ix. Macias, Santiago y Lopes, Maria da Conceição. «O território de Beja entre a Antigüedade Tardia e a islamizaçáo». En Caballero Zoreda, Luis; Mateos Cruz, Pedro y Cordero Ruiz, Tomás (eds.). Visigodos y omeyas: el territorio. Mérida: Consejo Superior de Investigaciones Científicas, 2012, pp. 305-328. Véase, asimismo, Ruiz Souza, Juan Carlos y Uscatescu, Alexandra. «El 'occidentalismo' de Hispania y la koiné artística mediterránea (siglos vII-VIII)». Goya. Revista de Arte, 2014, vol. 347, pp. 95-115. 
mezquita, que resultaría una de las más antiguas documentadas en la Península. Aunque la orientación podría asemejarse a la de las mezquitas levantadas en el siglo viII (Córdoba y Zaragoza $)^{46}$, solo podrá confirmarlo la arqueología. Será interesante comprobar, en el caso hipotético de que fuera una mezquita, si se hallaba en un entorno comercial o de cierta importancia urbana.

En el yacimiento de Tolmo de Minateda (Albacete), identificado como la sede episcopal visigoda de Elo, la Madinat Iyyih de los textos árabes, solo se documentan transformaciones que delatan la islamización y la arabización progresiva de la población a partir del final del siglo viII. Si bien todavía no se ha encontrado la mezquita aljama del lugar, en 2014 apareció una botella de tipología visigoda con una inscripción en árabe en la que se lee «Ibn Nabdak se dirigió a la mezquita», lo que confirmaría que los conquistadores erigieron un oratorio ${ }^{47}$. El área mejor conocida del enclave es el conjunto episcopal, con la iglesia y el palacio, por lo que hemos de pensar que los musulmanes eligieron un lugar diferente y seguramente alejado del mismo para instalar la mezquita.

Las dudas que se planteaban sobre el mausoleo romano de Las Vegas de La Pueblanueva (Toledo) y su conversión posterior en mezquita, según el estudio publicado por Hauschild en 1978, son ahora más irresolubles porque el pequeño ábside identificado como posible mị̂rāb fue destruido poco después de aquella publicación al ser abandonado el yacimiento. Un estudio arqueológico reciente del edificio mantiene las dudas sobre la cronología de aquel elemento y, por tanto, sobre su identificación como mihrrā $b^{48}$.

Un segundo caso de posible conversión se ha hallado en Los Hitos, Arisgotas (Toledo). El conjunto, construido a partir del siglo vi, era una villa fortificada de la alta aristocracia hispanovisigoda de Toledo ${ }^{49}$. Además del imponente pabellón áulico, se han excavado una iglesia y un edificio tripartito que abre a un patio y a una plaza. El conjunto, fechado entre finales del siglo vi y el viI, fue abandonado en el viII y reocupado durante los siglos x y XI, según Jorge Morín. La iglesia, excavada en la campańa de $2017^{50}$, era un edificio de nave única abovedada, lujosamente decorado con canceles y placas de mármol en los zócalos y parte del pavimento. Además, contaba con un espacio funerario

46 Henning, Joachim et ál. «Reccopolis revealed: the first geomagnetic mapping of the early medieval Visigothic royal town». Antiquity, 2019, vol. 93, n. ${ }^{3}$ 369, p. 742 . Véase la figura de K. Rassmann \& H. Höhler-Brackmann.

47 Gamo Parras, Blanca y Gutiérrez Lloret, Sonia. «El Tolmo de Minateda entre la Tardía Antigüedad y la Alta Edad Media: nuevos retos en nuevos tiempos». En Perlines Benito, María y Hevia Gómez, Patricia (eds.). La Meseta Sur entre la Tardia Antigüedad y la Alta Edad Media. Toledo: Junta de Comunidades de Castilla-La Mancha, 2017, p. 63.

48 Llave Muñoz, Sergio de la y Escobar Requena, Ana. «Redescubriendo el mausoleo tardorromano de Las Vegas (La Pueblanueva, Toledo)». Urbs Regia, 2017, vol. 2, p. 40.

49 Barroso, Rafael; Morín de Pablos, Jorge et ál. «Toletum. Configuración y evolución urbana de la capital visigoda y su territorio». En Sánchez Ramos, Isabel y Mateos Cruz, Pedro (coords.). Territorio, topografía y arquitectura de poder durante la Antigüedad Tardia. Mérida: Consejo Superior de Investigaciones Científicas-Instituto de Arqueología de Mérida, 2018, pp. 220-225. Agradezco a J. Morín que pusiera a mi disposición todos los datos.

50 Morín, Jorge. «Excepcional hallazgo arqueológico en Toledo: descubren una iglesia 'privada'». El Digital CLM- EFE, 11 de diciembre de 2017; ÍDEM. «Las excavaciones en Los Hitos revelan una villa fortificada única». La Tribuna, Domingo 18 de agosto de 2019. 
propio y con dos pórticos que convertían la planta en una cruz latina. Según Morín, la iglesia se transformaría en una pequeńa mezquita rural con la apertura de un mị̣rāb en el muro oriental de la cabecera, si bien este aparece descentrado hacia el norte y con una orientación al noreste. Se conservan los cimientos de un gran nicho rectangular con las esquinas ligeramente redondeadas (Fig. 3).

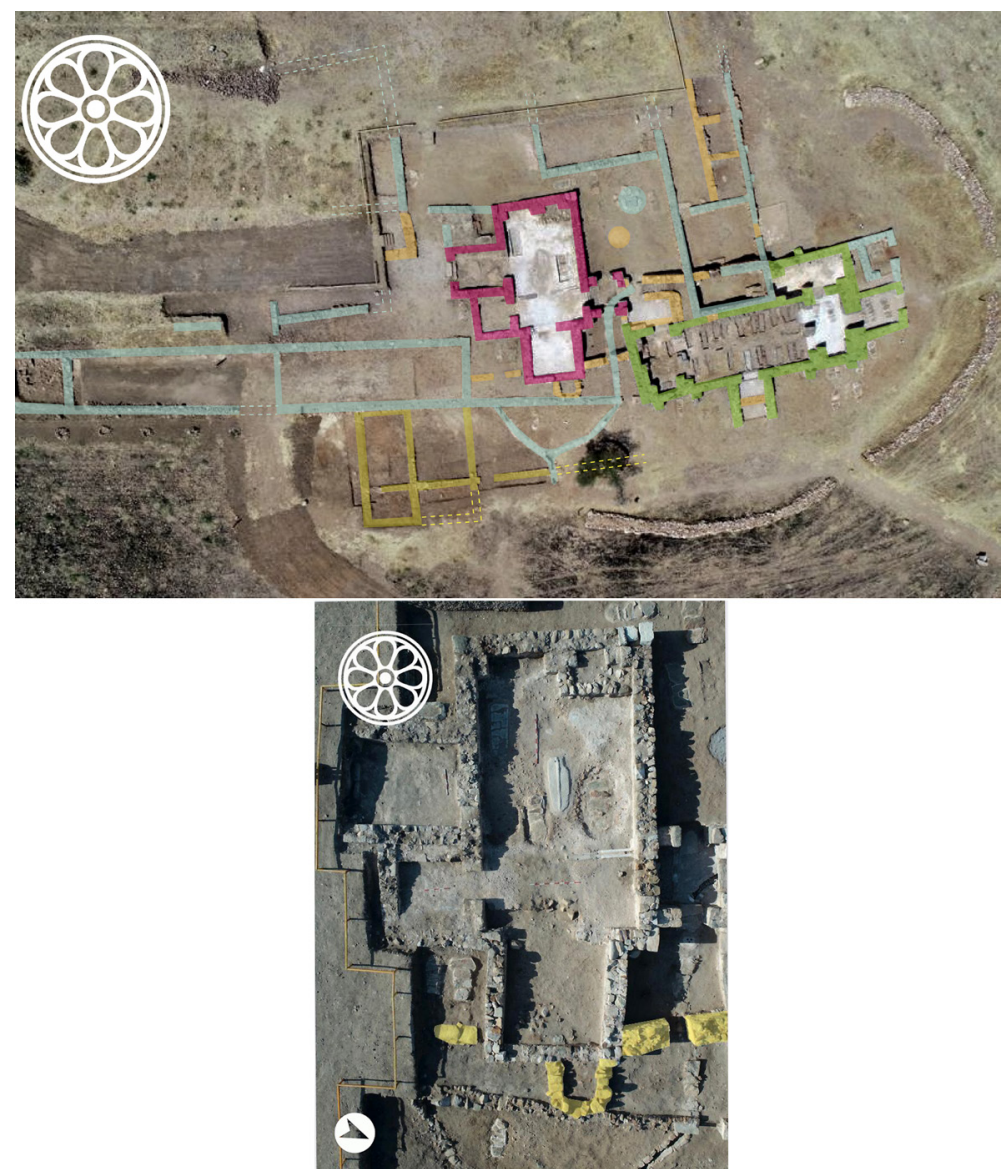

Figura 3. Los Hitos, Arisgotas (Toledo). Fotos de J. Morín.

Seguimos sin conocer bien las estructuras sobre las que se levantó la mezquita aljama de Córdoba, aunque suele aceptarse la existencia de una iglesia cercana ${ }^{51}$. Las excavaciones de los años 30 del siglo xx encontraron restos de edificios tardoantiguos e hispanovisigodos que indican una ocupación importante. En las excavaciones que Marfil

51 Calvo Capilla, Las mezquitas, pp. 55-56. 
dirigió entre 1996 y 1997 en el patio de la aljama, junto a las puertas de las naves más occidentales de la sala de oración (área correspondiente a la primera mezquita), también se encontró un pavimento exterior y, en él, un conjunto numismático de feluses emirales previos al 143H/760, anteriores por tanto a la construcción de la mezquita. También se hallaron estructuras de los siglos vi y viI ${ }^{52}$. Un hallazgo similar se produjo en 2017, cuando se encontraron otros dieciocho feluses de las mismas fechas en el área del acceso a la tercera nave desde la fachada occidental (nave 17). No se pudo documentar claramente el horizonte de construcción ni estructuras previas, pero sí el pavimento de grava y cantos de río que hubo en el patio de la mezquita fundacional y el de tierra batida del interior de la sala de oración ${ }^{53}$. El conjunto de hallazgos indica un área urbana con edificios de cierta importancia (¿un barrio episcopal?) y de su análisis detallado podrán extraerse interesantes informaciones sobre el solar en el que se levantó la mezquita aljama atribuida a 'Abd al-Rahman I.

Una vez recorridos todos estos lugares, surge, paradójicamente, esta pregunta: ¿cómo y dónde rezaban las primeras comunidades islamizadas tanto en el Mediterráneo como en al-Andalus? ¿En qué consistían las primeras masāŷid o lugares de prosternación? Dado que, como se ha visto, son escasos los restos materiales de los primeros oratorios, parece necesario abordar el «cómo rezaban», incluso el «qué rezaban».

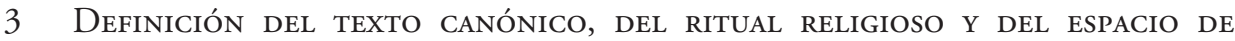 ORACIÓN}

Los estudios de los manuscritos coránicos más antiguos, así como de las inscripciones y de otros textos preislámicos o del islam temprano encontrados en el Próximo Oriente y la península arábiga, escritos en diferentes lenguas semíticas, han permitido a los especialistas en los últimos años replantear tanto la fecha como el proceso mediante el que se estableció la versión canónica del Corán. Los exégetas y tradicionistas también aportan datos que hacen sospechar un largo y lento paso de la transmisión oral al texto escrito. De Prémare resumió bien esa transición indicando que en la primera mitad del siglo viII (siglo ir de la Hégira) todavía no se había establecido la versión canónica que hoy conocemos ${ }^{54}$. Déroche, siguiendo a la tradición religiosa, sitúa en época del califa 'Uțmān (23-35H/644-656) el primer intento de compilación para acabar con las

52 Las monedas son epigráficas y en árabe, con la profesión de fe en el anverso y la misión profética en el reverso: Frochoso Sánchez, Rafael. «Las monedas encontradas en las excavaciones de la Catedral de Córdoba». Arte, Arqueología e Historia, 2009, vol. 16, p. 195. Marfil, Pedro. "Intervención arqueológica en el Patio de los Naranjos de la Catedral de Córdoba, antigua Mezquita Aljama». Qurtuba, 1997, vol. 2, pp. 334-335.

53 Fernández Cabrera, Daniel; León Pastor, Enrique y Ortiz Urbano, Raimundo. Actividad Arqueológica Preventiva. Control Arqueológico. Puerta-Celosía Nave 17 Conjunto Monumental Mezquita-Catedral de Córdoba. Memoria preliminar. Córdoba, Septiembre de 2017, en https://mezquita-catedraldecordoba. es/investigacion/otros-proyectos/ (consultado el 28/09/2019), pp. 74-76.

54 Prémare, Alfred-Louis de. Aux origines du Coran, questions d'hier, approches d'aujourd'hui. Paris: Téraèdre («L'Islam en débats»), 2004, p. 97. 
versiones divergentes que circulaban entre la comunidad de creyentes. Este califa enviaría ejemplares a las principales ciudades, al igual que se hizo en tiempos de 'Abd al-Malik y al-Walìd, cuando se produjo un nuevo impulso en la fijación del Corán escrito. En paralelo se intentaba, asimismo, fijar la manera canónica de leerlo o recitarlo (qiräa $)^{55}$. Pero las cuestiones de la cronología del Corán y de los «autores» del corpus coránico están lejos de ser resueltas y necesitan superar los enfoques tradicionales, como indica recientemente Dye ${ }^{56}$.

Las inscripciones «coránicas» del deambulatorio de la Cúpula de la Roca de Jerusalén (que proporcionan la fecha de 72H/691-692) suelen mencionarse en los estudios dedicados a la cronología del texto sagrado para documentar el proceso de canonización del mismo. Tampoco debe olvidarse que es el edificio más antiguo que conocemos donde se usa la epigrafía árabe con este carácter monumental decorativo. Para Whelan, aunque los versículos de la Cúpula de la Roca no coinciden con la 'Vulgata', y «el estilo paleográfico de las inscripciones es muy distinto de los ejemplos más antiguos de escritura árabe en cualquier medio», el complejo discurso político-religioso fabricado mediante citas de pasajes del contexto coránico sugiere, en su opinión, «una amplia familiaridad con ellos y con las implicaciones que éstos tenían para la comunidad islámica primitiva» de la época de 'Abd al-Malik. Grabar añade algo importante: la selección debió estar condicionada por la tradición oral del ambiente, dado su carácter retórico y similar al que define las plegarias. Para Al-Azmeh «estaríamos ante la circulación de material de carácter canónico, y por lo tanto completamente coránico, antes del establecimiento de un canon literario formalmente sellado, lo cual necesitó de un largo proceso de elaboración ${ }^{57}$.

55 Déroche, François. Le Coran, une histoire plurielle. Essai sur la formation du texte coranique. Paris: Seuil, 2019, caps. 2 y 3. En las últimas décadas han sido publicadas interpretaciones más controvertidas respecto a la formación del islam y del texto coránico, como los trabajos de Crone, Patricia y Cook, Michael. Hagarism: The Making of the Islamic World. Cambridge: Cambridge University Press, 1977; y LuXenberG, Christoph. "A New Interpretation of the Arabic Inscription in Jerusalem's Dome of the Rock». En OHLIG, Karl-Heinz y Puin, Gerd-R. (eds.). The Hidden Origins of Islam. Amherst, NY: Prometheus Books, 2010, pp. 125-151. Es interesante recordar asimismo los estudios de Ch. J. Robin sobre el contexto en el que surge, una Tardo Antigüedad que impregnaba asimismo la península arábiga, "L’Arabie préislamique». En Dye, Guillaume y Amir-Moezzi, Mohammad (dirs.). Le Coran des historiens: Volume 1. Etudes sur le contexte et la genèse du texte coranique. Paris: Éditions du Cerf, 2019, pp. 51-154.

56 Dye, Guillaume. «Le corpus coranique: contexte et composition». En Dye, Guillaume y AmirMoezzi, Mohammad (dirs.). Le Coran des historiens: Volume 1. Études sur le contexte et la genèse du texte coranique. Paris: Éditions du Cerf, 2019, pp. 822-823.

57 Azmen, Aziz Al-. The Emergence of Islam in Late Antiquity: Allāh and His People. Cambridge: Cambridge University Press, 2014, p. 460; Whelan, Estelle. "Forgotten witness: Evidence for the early codification of the Qur'àn». The Journal of the American Oriental Society. American Oriental Society, 1998, vol. 118, n. ${ }^{\circ}$ 1, pp. 10-13; Grabar, Oleg. The shape of the Holy: Early Islamic Jerusalem. Princeton, NJ: Princeton University Press, 1996, pp. 63-68; LuxenberG, "A New Interpretation». Otras aportaciones sobre las inscripciones de la Cúpula de la Roca: George, Alain. The Rise of Islamic Calligraphy. London: Saqi Books, 2010, pp. 60-68; y Milwright, The Dome of the Rock, pp. 160-171, donde se analiza la forma y la cronología de las dos inscripciones del deambulatorio. Sobre el uso de la lengua árabe en ese momento inicial y sus motivaciones no religiosas, detalle importante, véase Bashear apud NeEs, Perspectives, p. 153. Este autor defendió dos procesos que convergen en la formación del islam como movimiento religioso: la islamización del (movimiento) político árabe y la arabización de la nueva religión (BAsHear, Suliman. Arabs and Others in Early Islam. Princeton, NJ: Darwin Press, 1997, pp. 53 y ss., 116). 
Junto al Corán, la segunda fuente religiosa y de derecho del Islam es la sunna o tradición del Profeta. Los hadices (hadit ), transmitidos de manera oral, probablemente se empezaron a sistematizar en época del califa 'Umar (II) b. 'Abd al- 'Azizz (99-101H/717719) en un intento de compilar las tradiciones que tenían garantizada la cadena de transmisión y acabar así con las grandes discordancias existentes. El proceso de textualización de la tradición se llevó a cabo a lo largo del siglo in de la Hégira (siglo ix) en forma de colecciones de hadices, como la de al-Bujārī (m. 256H/870), o de biografías de Muhammad (Sira). La literatura de hadices, o dichos del Profeta, comenzó a llegar a al-Andalus a finales del siglo ir de la Hégira (principios del siglo Ix), en parte gracias a la difusión de la Muwatța' escrita por Mālik b. Anas (m. 179H/795), fundador de la escuela jurídica Mālikī, que se convertirá en la dominante en al-Andalus. Este libro no era solo una obra jurídica, sino, sobre todo, un manual de ritual y práctica religiosa (acorde al consenso de la comunidad de Medina) y una compilación de hadices. De la mano de la tradición también llegó a al-Andalus una de las formas canónicas de lectura del Corán (qiräa), la del almocrí Nāifi', de Medina. En el siglo ix se desarrollaron asimismo los estudios andalusíes sobre hadices, con 'Abd al-Malik b. Habïb (c 174-238H/790-853) como figura destacada ${ }^{58}$.

Como se ve, la redacción en lengua árabe y la formación del corpus de textos canónicos ${ }^{59}$ fueron labores básicamente iniciadas y dirigidas por los omeyas, a quienes se les pueden atribuir otros dos aspectos relacionados con nuestro tema: la institución de unas prácticas litúrgicas ('ibādāt), empezando por el número de oraciones diarias y el ritual de la oración del viernes (șalät al-ŷmu'a a ${ }^{60}$, así como de una tipología básica de oratorio (masyiid), con sus elementos más identificativos: el patio, el alminar, la quibla y el mihhräb. Vamos a detenernos en tres de esos elementos: la șalāt u oración ritual, la orientación del rezo, es decir, de la quibla y el nicho abierto en dicho muro: el mi hrāb.

En el Corán no se dan detalles precisos de la oración de los viernes ni de las cinco oraciones diarias; tampoco se especifican las características del ayuno ni de la peregrinación,

58 Schacht, J. «Mālik b. Anas». En Bearman, P.; Bianquis, Th.; Bosworth, C. E.; Donzel, E. van y Heinrichs, W. P. (eds.). Encyclopaedia of Islam, Second Edition. Leiden: Brill, 1991, vol. 6, p. 264 (Kitāb al-Muwatta); Fierro, Isabel. "The introduction of hadith in al-Andalus (2nd/8th-3rd/9th centuries)». Der Islam, 1989, vol. 66, n. ${ }^{\circ}$ 1, pp. 68-93. La jutba o sermón, uno de los elementos más sobresalientes del ritual musulmán, junto con la oración del viernes, se hace derivar de las tradiciones proféticas y del Corán: ver JoNEs, Linda G. The Power of Oratory in the Medieval Muslim World. Cambridge: Cambridge University Press, 2012, pp. 21-23.

59 También la caligrafía y la propia lengua árabe estaban en «formación» (véase PrÉmARE, Aux origines du Coran; y Faizer, Rizwi. "The Dome of the Rock and the Qur'ān». En Mohammed, Khaleel y Rippin, Andrew (eds.). Coming to terms with the Qur'an: a volume in honor of professor Issa Boullata. North Haledon, NJ: Islamic Publications International, 2007).

60 Hawting, Gerald. «Introduction. The Development of Islamic Ritual». En Hawting, Gerald (ed.). The Development of Islamic Ritual. London: Routledge, 2006, pp. XIII-xxxıx; Monnot, G. «Ṣalāt». En Bearman, P.; Bianquis, Th.; Bosworth, C. E.; Donzel, E. van y Heinrichs, W. P. (eds.). Encyclopaedia of Islam. Second Edition. Leiden: Brill, 1995, vol. 8, pp. 925-934.; Meri, Josef W. "Ritual and the Qur'ān». En Encyclopaedia of the Qur'ān. Leiden: Brill, 2005, vol. 4, pp. 488-490. 
lo que indicaría que la liturgia se fue desarrollando de manera lenta a lo largo del periodo omeya y posterior. Invocación, oración y prosternación, realizadas con unas formas y ritmos precisos $\left(r a k^{\prime} a\right)$ y precedidas de un ritual de llamada $(a \underline{d} \bar{a} n)$ y purificación $(w u d \underline{u})$, fueron evolucionando desde prácticas arábigas, judías y cristianas ${ }^{61}$. Es significativo que los términos șalāt y mihrrāb no son de origen árabe ${ }^{62}$. Varios autores árabes indican que al principio los creyentes solo tenían obligación de rezar dos veces al día, al amanecer y al atardecer ${ }^{63}$. Aunque la acción de rezar aparece a menudo en el Corán, fue la tradición islámica posterior la que, remontándose a la vida del Profeta mediante los hadices ${ }^{64}$, elaboró todo un corpus litúrgico ${ }^{65}$. El desarrollo de un ritual propio dotaba al nuevo monoteísmo de un factor de identidad respecto al resto de las doctrinas ${ }^{66}$. Sin embargo, en esa vuelta atrás, como indica Robin, los tradicionistas musulmanes del siglo viII tenían un conocimiento muy precario de los periodos preislámico y del primer islam, también en lo que respecta al ritual ${ }^{67}$.

Así, la tradición islámica sitúa la consolidación de la práctica litúrgica de la oración justo después del cambio de quibla o de la dirección del rezo. Los primeros creyentes no rezaban hacia La Meca, según el propio Corán (2:142-145), sino hacia un lugar identificado como Jerusalén por la tradición profética ${ }^{68}$. La mudanza de la dirección hacia el sur se produjo, según los exégetas, aún en vida de Muhammad; pero parece más lógico pensar que fue generaciones después, al tiempo que se ponía por escrito el Corán ${ }^{69}$. En cualquier caso, como advierte King, lo importante no es saber si una orientación es correcta hoy, sino definir qué dirección o direcciones se consideraban adecuadas para las quiblas en el periodo en que empiezan a construirse las primeras mezquitas monumentales. Por lo general, aquellas no miraban hacia La Meca sino que reproducían los

61 Donner, Muhammad and the believers, pp. 214-216; Becker, Carl Heinrich. "On the History of early Muslim Worship». En Hawting, Gerald (ed.). The Development of Islamic Ritual. London: Routledge, 2006, pp. 25-26; Gaffney, Patrick D. «Friday Prayer». En Encyclopaedia of the Qur'ān. Leiden: Brill, 2005, vol. 2, pp. 271-272; Hoyland, Robert G. In God's Path: The Arab Conquests and the Creation of an Islamic Empire. Oxford: Oxford University Press, 2015, pp. 228-229; Dye, Guillaume. "Jewish Christianity, the Qur'ān, and Early Islam: Some methodological caveats». En Río Sánchez, F. del (ed.). Jewish Christianity and the Origins of Islam Papers presented at the Colloquium held in Washington DC, October 29-31, 2015 (8th ASMEA Conference). Turnhout: Brepols, 2018, pp. 11-29.

62 Katz, Marion Holmes. Prayer in Islamic Thought and Practice. Cambridge: Cambridge University Press, 2013, pp. 11-14. En la poesía yemení, miḥrāb significaba edificio, palacio, lugar del príncipe o sala de audiencia, Robin, «L'Arabie préislamique», p. 90.

63 Rubin, Uri. "Morning and Evening Prayers in Early Islam». Jerusalem Studies in Arabic and Islam, 1987, vol. 10, pp. 40 y 53-54.

64 Monnot, «Ṣalāt», p. 926.

65 Katz, Prayer, pp. 18-19.

66 Hawting, "Introduction», pp. XXXI-XXXIV.

67 Robin, «L'Arabie à la veille de l'Islam», pp. 295-296.

68 Calvo Capilla, "Justicia, misericordia y cristianismo", pp. 176-177.

69 Donner, Muhammad and the believers, pp. 214-224. 
ejes astronómicos de la Ka'ba, una estructura rectangular astronómicamente alineada ${ }^{70}$. Más tarde, para la sociedad islámica medieval, la Ka'ba estaba en el centro de la geografía sagrada con las quiblas de las diferentes regiones alrededor.

En referencia a los primeros lugares de oración, las fuentes indican que hubo una primera quibla, llamada qibla mušarriqa, dirigida hacia el este, que Bashear identificó con la orientación de las iglesias. En su opinión, esta se abandonó por la «verdadera quibla del islam» antes de las grandes construcciones omeyas, el momento de definición de los espacios de oración ${ }^{71}$.

Para Di Cesare la qibla mušarriqa tendría otro sentido, expuesto en su reciente reinterpretación de la primera fase de la mezquita al-Aqsa de Jerusalén, cuya construcción sitúa en los años 40-60H/660-680. La autora analiza las mezquitas más antiguas como la fundada por 'Amr en Fustat, que según las fuentes tenía una orientación «muy al este» (mušarriqa ŷiddan), y concluye que esas orientaciones (90 respecto a la dirección del orto de Canopo) coincidían también con la alineación astronómica de la Ka'ba, de ahí que se consideraran válidas, algo que concuerda con lo explicado por King. Su segunda conclusión, sin embargo, es más discutible: que estas mezquitas construidas de manera «más compleja» y sólida conservaron «la orientación previa» (hacia el este) de las "primeras mezquitas» (earliest mosques) a las que sustituían, asumiendo sin bases materiales que hubo unas mezquitas más antiguas y que aquellas estaban orientadas asimismo al este ${ }^{72}$.

En su última publicación King retoma la hipótesis, ya apuntada por otros investigadores como Bonine o Marfil, de que la quibla de la mezquita de Córdoba, al igual que otras en el Norte de África, mira al sur porque el edificio se alineó con las calles principales de la Colonia Patricia de la ciudad romana, alineadas, a su vez, con los ejes solsticiales ${ }^{73}$. La orientación del viario ortogonal romano coincidía por ello con la alineación astronómica de la Ka'ba. Pero, aunque la orientación del eje de la Ka'ba era muy importante, King sugiere que la mezquita fue orientada al sur siguiendo el trazado urbano de la Colonia Patricia y que, al mismo tiempo o más tarde, se vio que coincidía con la alineación de la Ka 'ba, dotando así a su quibla de una «cobertura sagrada» o justificación religiosa, y asociándola con los conquistadores, es decir, de nuevo con aquellos legendarios $t \bar{a} b i^{\top} \bar{u} n^{74}$.

70 KING, David A. «The enigmatic orientation of the Great Mosque of Córdoba». Suhayl. International Journal for the History of the Exact and Natural Sciences in Islamic Civilisation, 2018-2019, vol. 16-17, pp. 35 y 44 .

71 BASHEAR, «Qibla musharriqa», pp. 281-282

72 Di CESARE, "A qibla mušarriqa», pp. 89-91.

73 Bonine, Michael E. «Romans, astronomy and the qibla: urban form and orientation of Islamic cities of Tunisia». En Holbrook, Jarita C., Medupe, Rodney Thebe y Urama, Johnson O. (eds.). African Cultural Astronomy - Current Archaeoastronomy and Ethnoastronomy Research in Africa. Berlin: Springer, 2008, pp. 145-178, apud KING, "The enigmatic orientation», pp. 35-48.

74 KInG, «The enigmatic orientation», p. 35-37 y 81. Calvo Capilla, «Las primeras mezquitas», pp. 166-170: «Al-Rāzī atribuye explícitamente "el trazado de los cimientos” de la primera mezquita (asās mujtațt 
Si bien la coincidencia pudo existir en Córdoba (también lo es en Damasco), no estoy segura de que la supuesta alineación de las calles de la ciudad romana fuera totalmente determinante a la hora de establecer la orientación de la quibla de su aljama. Cuando ese trazado urbano no se acomodaba a sus necesidades, se giraba el edificio de la mezquita para orientarlo de la manera que creían correcta, como sucedió por ejemplo en Zaragoza, que precisamente tiene una orientación semejante a Córdoba y Qayrawan, perpendicular al eje solsticial que une el orto del Sol en verano y su ocaso en invierno ${ }^{75}$. No parece que la orientación de la quibla fuera dejada a la casualidad ni en Zaragoza ni en otros lugares como Gerasa o Palmira. En Gerasa, para orientar correctamente la quibla de la mezquita, todo el edificio se giró ligeramente respecto a la trama urbana, quedando en ángulo respecto al decúmano sur. Lo mismo sucedió en Palmira.

En definitiva, no tenemos certeza absoluta de la dirección hacia la que rezaron los primeros musulmanes de la Península antes de la construcción de esas mezquitas a finales del siglo viII.

Recientemente, Di Cesare ha ligado la aparición del miḩrāb muŷawwaf, en forma de nicho profundo, a la fijación de la quibla orientada al sur, lo que se produjo a inicios del siglo viII con la construcción de grandes mezquitas por orden del califa omeya al-Walīd b. 'Abd al-Malik. Suele admitirse que los primeros ejemplares de miḩräb-s fueron precisamente los erigidos en las mezquitas de Medina y Damasco por orden de al-Walìd entre el ańo $87 \mathrm{H} / 706$ y el $96 \mathrm{H} / 714-715^{76}$. En este sentido, hemos de considerar un anacronismo de los autores árabes las alusiones al mihrāb cóncavo de las mezquitas fundadas por los conquistadores $^{77}$. Aunque algunos investigadores han propuesto la existencia previa de miḥāb-s pintados o arcos tallados en bloques monolíticos de piedra, no hay restos arquitectónicos. Por eso son de gran interés el Corán de Saná (Yemen), con dos ilustraciones de arquitecturas en forma de mezquita, y las acuñaciones tipo mị̂rāb con una lanza ('anaza) en su interior de época de 'Abd al-Malik, ambas cosas de fechas inmediatas a las construcciones de al-Walīd ${ }^{78}$ (Fig. 4).

al-masŷid al-mubārak) a los conquistadores (al-fätihīin), refiriéndose a los árabes llegados con Mūsà (incluidos los täbi $\left.{ }^{\prime} u ̈ n\right)$ o a los primeros gobernadores de al-Andalus (711-755)».

75 Rius, Mònica. La alquibla en al-Andalus y al-Magrib al-Aqșà. Barcelona: Institut Millás Vallicrosa d'Història de la Ciència Àrab, 2000, pp. 174-188. La fachada este del Alcázar de Córdoba, sin embargo, tiene una orientación diferente: Murillo Redondo, Juan Francisco et ál. «Investigaciones arqueológicas en la muralla de la Huerta del Alcázar (Córdoba)». Anejos de Anales de Arqueología Cordobesa, 2009-2010, vol. 2, pp. 218-219.

${ }^{76}$ Creswell, K. A. C. A Short Account of Early Muslim Architecture (revised and supplemented by James W. Allan). Cairo: The American University in Cairo Press, 1989 (1. ${ }^{a}$ ed. 1958), pp. 43-46. Flood planteó que los primeros mihräb-s de las mencionadas mezquitas de Damasco y de Medina pudieron tener forma de venera: Flood, Finbarr Barry. The Great Mosque of Damascus. Leiden-Boston-Köln: Brill, 2001, pp. 47-56. Véase con más detalle en Calvo Capilla, Las mezquitas, pp. 57-59.

77 Whelan, «Forgotten witness», pp. 205-223.

78 Para el Corán: George, The Rise of Islamic Calligraphy, pp. 79-86. El arco interpretado como sacrum, espacio que alberga lo sagrado en los tres monoteísmos: TrEaDWell, Luke. «Mihrab and 'Anaza' or 'Sacrum and Spear'? A Reconsideration of an Early Marwanid Silver Drachm». Muqarnas, 2005, vol. 22, pp. $19-22$. 


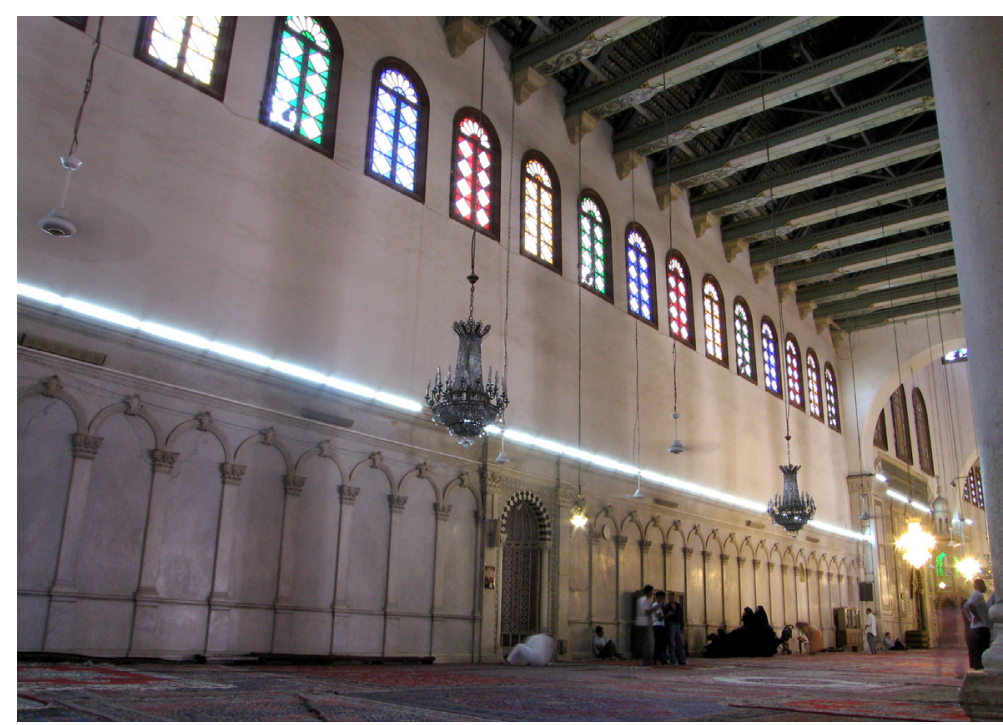

FIgURA 4. Mezquita de Damasco. Quibla en el estado actual. Foto de la autora.

\section{Conclusiones}

La ausencia de datos sobre los primeros oratorios obligó a los cronistas omeyas a inventar mitos fundacionales, a imaginar unos hechos y darles una explicación que permitiese sentar unas bases sólidas y verdaderas del islam y de la ortodoxia de la práctica religiosa andalusíes.

¿Por qué no hay rastro de las primeras mezquitas de las tierras conquistadas por el islam? ¿Buscamos edificios de culto de un modelo y una orientación anacrónicos? En definitiva, ¿sabemos lo que buscamos cuando hablamos de «primeras mezquitas»?

Parece necesario, como decíamos, abordar el tema del grado de islamización de los conquistadores. Es significativo que las acuńaciones de los nuevos gobernantes en 93H/711-712, en el momento de la conquista del reino hispanovisigodo, fueran en latín e introdujeran una fórmula monoteísta como es «En el nombre de Dios, no hay dios sino Dios», sin alusiones a ningún profeta, pero con la fecha de la Hégira ${ }^{79}$. Eran monedas legibles para la población local con un mensaje que proclamaba la existencia de un único Dios. Cuando los conquistadores empiezan en 98H/716 a acuñar solidus bilingües (latín y árabe) se mantiene la fórmula monoteísta en latín e introducen en árabe los nombres del profeta y del territorio: Muhammad y al-Andalus ${ }^{80}$, traducción de Hesperis-Hispania, un

79 IN Nomine Dei Non Deus NiSi Deus SoLuS Non Similis. En el reverso se menciona la ceca de Spania: Novus SoLiDus FeRiTus In SPaNia ANNo XCIII - INDiCción XI («Nuevo sólido hecho en Hispania año 93 - Indicción XI» = año $93 \mathrm{H}=711-712$ ).

80 Muhammad rasūl allāh (Muhammad es el enviado de Dios). 
mensaje que solo los conquistadores árabes podían leer y que constituiría una prueba de su acción político-militar de cara a Damasco, al igual que los sellos de plomo o precintos, pruebas del control de la actividad fiscal y comercial y de la organización administrativa en el nuevo territorio. Hasta el 101H/720 no aparece el dinar enteramente epigráfico en árabe y desaparece la estrella del anverso ${ }^{81}$; y hasta el $145 \mathrm{H} / 763$ no tenemos la primera emisión monetaria conocida de 'Abd al-Raḥmān I ${ }^{82}$. No está de más recordar que lo importante de las monedas que circulaban en la época no era la lengua en la que estaban escritas sino su valor, de ahí que los dinares omeyas se usaran, e incluso se imitaran, en lugares tan lejanos como el extremo septentrional de Europa ${ }^{83}$. Tanto la arabización como la islamización empezarían en breve a dar unos primeros pasos a lo largo del siglo VIII, pero a ritmo lento y con resultados diversos.

Una posible conclusión a todo lo expuesto en las páginas anteriores es que todo parece provisional y mudable durante casi sesenta ańos en la Península. Las acuñaciones del nuevo emir omeya en 763 podrían estar constatando un control administrativo y fiscal efectivo del territorio y el establecimiento de un estado omeya. Únicamente a partir de ese momento parece posible que comenzaran a sentarse también las bases para la islamización del territorio reuniendo los instrumentos necesarios: textos, ritos y espacios. Como hemos visto, todo ello estaba en proceso de formación en las tierras centrales del Islam en el año 711. En la década de los 80 comenzaría a construirse la mezquita aljama de la capital, Córdoba, y de otras ciudades como forma de consolidar el poder y para fomentar la sedentarización y la unidad de la comunidad de creyentes ${ }^{84}$. Hasta entonces habría que pensar que, si los hubo, esos lugares de oración eran de carácter igualmente provisional e improvisado, mientras que las iglesias permanecían abiertas para la población cristiana mayoritaria. Solo a finales del siglo viII sería evidente un cierto equilibrio entre las dos comunidades, los musulmanes son cada vez más y los cristianos menos, las iglesias empiezan a ser abandonadas y a reutilizarse.

81 Canto, Alberto. «Precintos». En García Moreno, Luis A. y Vigil-Escalera, Alfonso (coords.). 711, Arqueología e historia entre dos mundos. Alcalá de Henares: Museo Arqueológico Regional, 2012, vol. I, pp. 159-165. En el periodo de transición del latín al árabe (711-720) las monedas llevan una estrella que aludiría al propio territorio cuyo nombre pasaba a ser al-Andalus, sinónimo de Spania (Hispania) y Hesperis, "la estrella vespertina que desde época clásica se asociaba con occidente, en particular con Hispania» según Ramírez del Río, José. "Acerca del origen del topónimo al-Andalus». eHumanista/IVITRA, 2017, vol. 12, pp. 138-139.

82 Canto, Alberto. «Las monedas y la conquista». En García Moreno, Luis A. y Vigil-Escalera, Alfonso (coords.). 711, Arqueología e historia entre dos mundos. Alcalá de Henares: Museo Arqueológico Regional, 2012, vol. I, pp. 133-144. El modelo de acuñación había sido establecido por el califa 'Abd al-Malik en Damasco en el año 77H/697, con las fórmulas religiosas de la šahāda y la afirmación del Profeta: BACHARACH, Jere L. "Signs of Sovereignty: The Shahäda, Qur'anic Verses, and the Coinage of 'Abd al-Malik». Muqarnas, 2010, vol. 27, pp. 1-30. Sobre arabización e islamización, véase nota 57.

83 Moneda de oro de 774, acuńada por el rey Offa de Mercia (Inglaterra), a imitación del dinar abasí contemporáneo. Allan, John. "Offa's imitation of an Arab dinar». The Numismatic Chronicle and Journal of

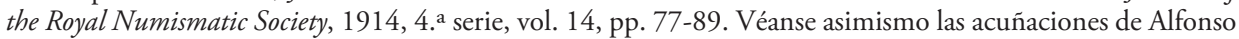
VIII en árabe.

84 Calvo Capilla, Las mezquitas, pp. 62-74. 
En definitiva, acuñar moneda con el nombre del profeta en 716 no significa que en esas fechas tanto el dogma (Corán y Sunna) como la liturgia estuvieran totalmente definidos y mucho menos consolidados, como se dijo antes. Hemos de preguntarnos cuál era el grado de islamización de las tropas árabes y beréberes que se instalaron en la Península a principios del siglo viII. La necesidad que tienen los cronistas posteriores, de finales del siglo IX y del $\mathrm{x}$, de insistir en la presencia de unos míticos täbiữn incrustados en las tropas llegadas en el $711 \mathrm{y}$ de atribuirles el trazado de las primeras quiblas de al-Andalus explicaría, en nuestra opinión, la limitada carga religiosa de la conquista y los escasos testigos que había dejado. La carencia de restos materiales, principalmente de edificios de culto en las primeras fases de desarrollo del Islam en todas las regiones (en el siglo viI en el Levante, en el siglo viII en el Magreb), confirma esta conclusión: ni la doctrina ni la liturgia debían estar plenamente definidas, al igual que la necesidad de unos espacios concretos con unos componentes determinados hoy reconocibles ${ }^{85}$. Fue a partir de la construcción (según las fuentes árabes reconstrucción ${ }^{86}$ ) de las mezquitas de las capitales, Damasco, Jerusalén, Medina o El Cairo, en época de al-Walīd, en las dos primeras décadas del siglo viII, cuando se establece un modelo duradero de edificio de culto que se extenderá masivamente a partir de entonces.

\section{REFERENCIAS BIBLIOGRÁFICAS}

Allan, John. "Offa's imitation of an Arab dinar». The Numismatic Chronicle and Journal of the Royal Numismatic Society, 1914, 4. ${ }^{\mathrm{a}}$ serie, vol. 14, pp. 77-89.

Antun, Thallein. The Architectural Form of the Mosque in the Central Arab Lands, from the Hijra to the End of the Umayyad Period, 1/622-133/750. Oxford, BAR International Series 2790, 2016.

Avner, Rina. "The Dome of the Rock in light of the development of concentric Martyria in Jerusalem: Architecture and Architectural Iconography». Muqarnas, 2010, vol. 27, pp. 31-50.

Avni, Gideon. The Byzantine-Islamic Transition in Palestine. An Archaeological Approach. Oxford: Oxford University Press, 2014.

Azmen, Aziz Al-. The Emergence of Islam in Late Antiquity: Allāh and His People. Cambridge: Cambridge University Press, 2014.

Bacharach, Jere L. «Signs of Sovereignty: The Shahāda, Qur'anic Verses, and the Coinage of 'Abd al-Malik». Muqarnas, 2010, vol. 27, pp. 1-30.

Baratte, François. «Recherches franco-tunisiennes sur la citadelle byzantine d'Ammaedara (Haïdra)». Comptes rendus des séances de l'Académie des Inscriptions et Belles-Lettres, 1996, vol. 140, n. ${ }^{\circ}$, pp. $125-154$.

85 RoBin, «L'Arabie à la veille de l'Islam»; Donner, Muhammad and the believers; AzmeH, The Emergence of Islam. Por el contrario, otros investigadores creen en la raíz plenamente islámica y coránica de los epígrafes en árabe (sobre todo la mención de Muhammad), tanto de las monedas como de los sellos de plomo comerciales de época de los gobernadores árabes, y consideran estos materiales indicio de que los conquistadores eran «verdaderos» musulmanes: GARcía SANJú́N, Alejandro. La conquista islámica de la Península Ibérica y la tergiversación del pasado. Del catastrofismo al negacionismo. Madrid: Marcial Pons, 2013, pp. 310-ss.

86 Antun, The Architectural Form, pp. 96-98. 
BARATte, François. «Les villes du nord de l'Afrique entre Antiquité tardive et conquête arabe. Historiographie récente et nouvelles perspectives». En Panzram, Sabine y Callegarin, Laurent (coords.). Entre civitas y madina. El mundo de las ciudades en la Península Ibérica y en el norte de África (siglos IV-IX). Madrid: Casa de Velázquez, 2018, pp. 191-202.

Barroso, Rafael; Morín de Pablos, Jorge et ál. «Toletum. Configuración y evolución urbana de la capital visigoda y su territorio». En Sánchez Ramos, Isabel y Mateos Cruz, Pedro (coords.). Territorio, topografía y arquitectura de poder durante la Antigüedad Tardía. Mérida: Consejo Superior de Investigaciones Científicas-Instituto de Arqueología de Mérida, 2018, pp. 195-236.

Bashear, Suliman. "Qibla musharriqa and Early Muslim Prayer in Churches». The Muslim World, 1991, vol. LXXXI, n. ${ }^{\circ} 2-3$, pp. 267-282.

Bashear, Suliman. Arabs and Others in Early Islam. Princeton, NJ: Darwin Press, 1997.

Becker, Carl Heinrich. "On the History of early Muslim Worship». En Hawting, Gerald (ed.). The Development of Islamic Ritual. London: Routledge, 2006, pp. 49-74 (traducción al inglés del artículo "Zur Geschichte des islamischen Kultus». Der Islam, 1912, vol. 3, p. 74-99).

Bonine, Michael E. «Romans, astronomy and the qibla: urban form and orientation of Islamic cities of Tunisia». En Holbrook, Jarita C., Medupe, Rodney Thebe y Urama, Johnson O. (eds.). African Cultural Astronomy - Current Archaeoastronomy and Ethnoastronomy Research in Africa. Berlin: Springer, 2008, pp. 145-178.

Calvo Capilla, Susana. «Las primeras mezquitas de al-Andalus a través de las fuentes árabes (92/711-170/785)». Al-Qantara, 2007, vol. 28, n. ${ }^{\circ} 1$, pp. 143-179.

Calvo Capilla, Susana. "Analogies entre les grandes mosquées de Damas et Cordoue: mythe ou réalité?». En Borrut, Antoine y Совв, Paul M. (eds.). Umayyad legacies: medieval memories from Syria to Spain. Leiden: Brill, 2010, pp. 281-311.

Calvo Capilla, Susana. "Justicia, misericordia y cristianismo: una relectura de las inscripciones coránicas de la Mezquita de Córdoba en el siglo X». Al-Qanțara, 2010, vol. 31, n. ${ }^{\circ} 1$, pp. 149-187.

Calvo Capilla, Susana. «Les premières mosquées et la transformation des sanctuaires wisigothiques (92H/711-170H/785)». Mélanges de la Casa de Velázquez, 2011, vol. 41, n. ${ }^{\circ}$ 2, pp. 131-163.

Calvo Capilla, Susana. Las mezquitas de al-Andalus. Almería: Fundación Ibn Tufayl de Estudios Árabes, 2014.

Canto, Alberto. «Las monedas y la conquista». En García Moreno, Luis A. y Vigil-Escalera, Alfonso (coords.). 711, Arqueología e historia entre dos mundos. Alcalá de Henares: Museo Arqueológico Regional, 2012, vol. I, pp. 133-144.

Canto, Alberto. «Precintos». En García Moreno, Luis A. y Vigil-Escalera, Alfonso (coords.). 711, Arqueología e historia entre dos mundos. Alcalá de Henares: Museo Arqueológico Regional, 2012, vol. I, pp. 159-165.

Creswell, K. A. C. A Short Account of Early Muslim Architecture (revised and supplemented by James W. Allan). Cairo: The American University in Cairo Press, 1989 (1. a ed. 1958).

Crone, Patricia y Cook, Michael. Hagarism: The Making of the Islamic World. Cambridge: Cambridge University Press, 1977.

Cytryn-Silverman, Katia. "The Umayyad mosque of Tiberias». Muqarnas, 2009, vol. 26, pp. $37-61$.

Cytryn-Silverman, Katia. Tibériade au début de l'ère islamique, 2009-2013. https://maxvanberchem.org/fr/activites-scientifiques/projets/archeologie/11-archeologie/36-city-centre-ofearly-islamic-tiberias (consulta: 15/08/2019). 
Cytryn-Silverman, Katia. «Tiberias' Houses of Prayer in Context». En Patrich, Joseph; PelegBarkat, Orit y Ben Yosef, Erez (eds.). Arise, walk through the land. Studies in the Archaeology and History of the Land of Israel in Memory of Yizhar Hirschfeld on the Tenth Anniversary of his Demise. Jerusalem: The Israel Exploration Society, 2016, pp. 235-248.

Déroche, François. Le Coran, une histoire plurielle. Essai sur la formation du texte coranique. Paris: Seuil, 2019.

Devreesse, Robert. «Le Christianisme dans le Sud palestinien». Revue des Sciences Religieuses, 1940, tome 20, fascicule 3-4, pp. 235-251.

Di Cesare, Michelina. «A qibla mušarriqa for the First al-Aqșà Mosque? A New Stratigraphic, Planimetric, and Chronological Reading of Hamilton's Excavation, and Some Considerations on the Introduction of the Concave mihräb». Annali dell'Università degli Studi di Na-

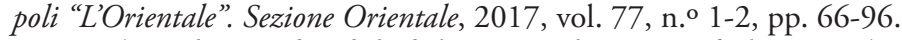

Donner, Fred. Muhammad and the believers. At the origins of Islam. Cambridge: Cambridge University Press, 2010.

Dye, Guillaume. "Jewish Christianity, the Qur'ān, and Early Islam: Some methodological caveats». En Río SÁnchez, F. del (ed.). Jewish Christianity and the Origins of Islam Papers presented at the Colloquium held in Washington DC, October 29-31, 2015 (8th ASMEA Conference). Turnhout: Brepols, 2018, pp. 11-29.

Dye, Guillaume. "Le corpus coranique: contexte et composition». En Dye, Guillaume y AmirMoezzi, Mohammad (dirs.). Le Coran des historiens: Volume 1. Études sur le contexte et la genèse du texte coranique. Paris: Éditions du Cerf, 2019, pp. 733-918.

Dye, Guillaume y Reynolds, Gabriel Said. «Sourate 72. al-Jinn (les djinns)». En Dye, Guillaume y Amir-Moezzi, Mohammad (dirs.). Le Coran des historiens: Volume 2b. Paris: Éditions du Cerf, 2019, pp. 1853-1867.

Faizer, Rizwi. "The Dome of the Rock and the Qur'ān». En Mohammed, Khaleel y Rippin, Andrew (eds.). Coming to terms with the Qur'ann: a volume in honor of professor Issa Boullata. North Haledon, NJ: Islamic Publications International, 2007.

Fenwick, Corisande. «Early Medieval Urbanism in Ifriqiya and the Emergence of the Islamic City». En Panzram, Sabine y Callegarin, Laurent (coords.). Entre civitas y madina. El mundo de las ciudades en la Peninsula Ibérica y en el norte de África (siglos IV-IX). Madrid: Casa de Velázquez, 2018, pp. 203-219.

Fernández Cabrera, Daniel; León Pastor, Enrique y Ortiz Urbano, Raimundo. Actividad Arqueológica Preventiva. Control Arqueológico. Puerta-Celosía Nave 17 Conjunto Monumental Mezquita-Catedral de Córdoba. Memoria preliminar. Córdoba, Septiembre de 2017, en https://mezquita-catedraldecordoba.es/investigacion/otros-proyectos/ (consultado el 28/09/2019).

Fierro, Isabel. «The introduction of hadith in al-Andalus (2nd/8th-3rd/9th centuries)». Der Islam, 1989, vol. 66, n. ${ }^{\circ}$ 1, pp. 68-93.

Flood, Finbarr Barry. The Great Mosque of Damascus. Leiden-Boston-Köln: Brill, 2001.

Frochoso Sánchez, Rafael. «Las monedas encontradas en las excavaciones de la Catedral de Córdoba». Arte, Arqueología e Historia, 2009, vol. 16, pp. 195-204.

Gaffney, Patrick D. «Friday Prayer». En Encyclopaedia of the Qur'än. Leiden: Brill, 2005, vol. 2, pp. 271-272.

Gamo Parras, Blanca y Gutiérrez Lloret, Sonia. «El Tolmo de Minateda entre la Tardía Antigüedad y la Alta Edad Media: nuevos retos en nuevos tiempos». En Perlines Benito, María y Hevia Gómez, Patricia (eds.). La Meseta Sur entre la Tardía Antigüedad y la Alta Edad Media. Toledo: Junta de Comunidades de Castilla-La Mancha, 2017, pp. 47-74. 
García Sanjuán, Alejandro. La conquista islámica de la Peninsula Ibérica y la tergiversación del pasado. Del catastrofismo al negacionismo. Madrid: Marcial Pons, 2013.

Genequand, Denis. «Al-Bakhra' (Avatha), from the Tetrarchic fort to the Umayyad castle». Levant, 2004, vol. 36, pp. 225-242.

Genequand, Denis. «An Early Islamic Mosque in Palmyra. Une mosquée du début de l'époque islamique à Palmyre». Levant, 2008, vol. 40, pp. 3-15.

George, Alain. The Rise of Islamic Calligraphy. London: Saqi Books, 2010.

Ghalia, Taher y Mahfoudh, Faouzi. "Aïn Tebournouk-Tubernuc et sa région de l'Antiquité tardive au Moyen Âge». Mélanges de l'École Française de Rome. Antiquité, 2003, vol. 115, n. ${ }^{\circ}$ 2, pp. 779-807.

Grabar, Oleg. The shape of the Holy: Early Islamic Jerusalem. Princeton, NJ: Princeton University Press, 1996.

Grabar, Oleg. The Dome of the Rock. Cambridge, MA: Harvard University Press, 2006.

GuidetTi, Mattia. In the Shadow of the Church: The Building of Mosques in Early Medieval Syria. Leiden: Brill, 2016.

Hawting, Gerald. «Introduction. The Development of Islamic Ritual». En Hawting, Gerald (ed.). The Development of Islamic Ritual. London: Routledge, 2006, pp. XIII-XXXIX.

HenNing, Joachim et ál. «Reccopolis revealed: the first geomagnetic mapping of the early medieval Visigothic royal town». Antiquity, 2019, vol. 93, n. ${ }^{\circ}$ 369, pp. 735-751.

Hoyland, Robert G. In God's Path: The Arab Conquests and the Creation of an Islamic Empire. Oxford: Oxford University Press, 2015.

Jones, Linda G. The Power of Oratory in the Medieval Muslim World. Cambridge: Cambridge University Press, 2012.

Katz, Marion Holmes. Prayer in Islamic Thought and Practice. Cambridge: Cambridge University Press, 2013.

KInG, David A. «The enigmatic orientation of the Great Mosque of Córdoba». Suhayl. International Journal for the History of the Exact and Natural Sciences in Islamic Civilisation, 2018-2019, vol. 16-17, pp. 33-111.

Llave Muñoz, Sergio de la y Escobar Requena, Ana. «Redescubriendo el mausoleo tardorromano de Las Vegas (La Pueblanueva, Toledo)». Urbs Regia, 2017, vol. 2, pp. 26-45.

Luxenberg, Christoph. "A New Interpretation of the Arabic Inscription in Jerusalem's Dome of the Rock». En Ohlig, Karl-Heinz y Puin, Gerd-R. (eds.). The Hidden Origins of Islam. Amherst, NY: Prometheus Books, 2010, pp. 125-151.

Macias, Santiago y Lopes, Maria da Conceição. «O território de Beja entre a Antigüedade Tardia e a islamização». En Caballero Zoreda, Luis; Mateos Cruz, Pedro y Cordero Ruiz, Tomás (eds.). Visigodos y omeyas: el territorio. Mérida: Consejo Superior de Investigaciones Científicas, 2012, pp. 305-328.

Mahfoudh, Faouzi. «Commerce de marbre et remploi dans les monuments de l'Ifriqiya médiévale». En Altekamp, Stefan; Marcks-Jacobs, Carmen y Seiler, Peter (eds.). Perspektiven der Spolienforschung 2. Zentren und Konjunkturen der Spoliierung. Berlin: Edition Topoi, 2017, pp. 15-42.

MarfiL, Pedro. «Intervención arqueológica en el Patio de los Naranjos de la Catedral de Córdoba, antigua Mezquita Aljama». Qurtuba, 1997, vol. 2, pp. 333-335.

Marín, M. "Șahāāba et tābi'ūn dans al-Andalus: histoire et légende». Studia Islamica, 1981, vol. 54, pp. 5-49.

Meri, Josef W. «Ritual and the Qur'ān». En Encyclopaedia of the Qur'ān. Leiden: Brill, 2005, vol. 4, pp. 484-498. 
Milwright, Marcus. The Dome of the Rock and Its Umayyad Mosaic Inscriptions. Edinburgh: Edinburgh University Press, 2016.

Monnot, G. "Șalāt». En Bearman, P.; Bianquis, Th.; Bosworth, C. E.; Donzel, E. van y Heinrichs, W. P. (eds.). Encyclopaedia of Islam. Second Edition. Leiden: Brill, 1995, vol. 8, pp. 925-934.

Moor, Bilha. "Mosque and Church: Arabic inscriptions at Shivta in the Early Islamic Period». Jerusalem Studies in Arabic and Islam, 2013, vol. 40, pp. 73-141.

Morín, Jorge. «Excepcional hallazgo arqueológico en Toledo: descubren una iglesia 'privada'». El Digital CLM- EFE, 11 de diciembre de 2017.

Morín, Jorge. "Las excavaciones en Los Hitos revelan una villa fortificada única». La Tribuna, Domingo 18 de agosto de 2019.

Murillo Redondo, Juan Francisco et ál. «Investigaciones arqueológicas en la muralla de la Huerta del Alcázar (Córdoba)». Anejos de Anales de Arqueología Cordobesa, 2009-2010, vol. 2, pp. 183-230.

Nees, Lawrence. Perspectives on Early Islamic Art in Jerusalem. Leiden: Brill, 2016.

Noth, Albrecht. The Early Arabic Historical Tradition. A Source-Critical Study. Second ed. in collaboration with Lawrence I. Conrad. Princeton, NJ: Darwin Press, 1994.

Pentz, Peter. The Invisible Conquest: The Ontogenesis of Sixth and Seventh Century Syria. Copenhagen: National Museum of Denmark, 1992.

Prémare, Alfred-Louis de. Aux origines du Coran, questions d'hier, approches d'aujourd'hui. Paris: Téraèdre («L'Islam en débats»), 2004.

Prevost, Virginie. «Des églises byzantines converties à l'islam? Quelques mosquées ibadites du djebel Nafûsa (Libye)». Revue de l'Histoire des Religions, 2012, vol. 3, pp. 325-347.

RAmírez Del Río, José. «Acerca del origen del topónimo al-Andalus». eHumanista/IVITRA, 2017, vol. 12, pp. 124-161.

Rattenborg, Rune y Blanke, Louise. "Jarash in the Islamic Ages (c. 700-1200 CE): a critical review». Levant, 2017, vol. 49, n. ${ }^{\circ}$ 3, pp. 312-332.

Rıus, Mònica. La alquibla en al-Andalus y al-Magrib al-Aqșà. Barcelona: Institut Millás Vallicrosa d'Història de la Ciència Àrab, 2000.

Roвın, Ch. Julien. «L'Arabie à la veille de l'Islam dans l'ouvrage de Aziz al-Azmeh. The Emergence of Islam in Late Antiquity». Topoi, 2017, vol. 21, pp. 291-320.

Robin, Ch. Julien. «L'Arabie préislamique». En Dye, Guillaume y Amir-Moezzi, Mohammad (dirs.). Le Coran des historiens: Volume 1. Etudes sur le contexte et la genèse du texte coranique. Paris: Éditions du Cerf, 2019, pp. 51-154.

Rubin, Uri. «Morning and Evening Prayers in Early Islam». Jerusalem Studies in Arabic and Islam, 1987, vol. 10, pp. 40-64.

Ruiz Souza, Juan Carlos y Uscatescu, Alexandra. «El 'occidentalismo' de Hispania y la koiné artística mediterránea (siglos viI-VIII)». Goya. Revista de Arte, 2014, vol. 347, pp. 95-115.

SACK, Dorothy. Resafa IV, Die Grosse Moschee von Resafa-Rusafat Hisam. Mainz: Deutsches Archäologisches Institut, 1996.

Schacht, J. «Mālik b. Anas». En Bearman, P.; Bianquis, Th.; Bosworth, C. E.; Donzel, E. van y Heinrichs, W. P. (eds.). Encyclopaedia of Islam, Second Edition. Leiden: Brill, 1991, vol. 6, pp. 262-265.

Seligman, Jon. «Solomon's Stables, the Temple Mount, Jerusalem: The Events Concerning the Destruction of Antiquities 1999-2001». Atigot, 2007, vol. 56, pp. 33-53.

St. Laurent, Beatrice y Awwad, Isam. "Archaeology \& Preservation of Early Islamic Jerusalem: Revealing the $7^{\text {th }}$ Century Mosque on the Haram Al-Sharif». En Proceedings of the 
9th International Congress of the Archaeology of the Ancient Near East, Islamic Session (edited by D. Genequand). Wiesbaden: Harrassowitz, 2016, pp. 469-478. https://vc.bridgew.edu/ art_fac/9/

Toral-Niehoff, Isabel y León Muñoz, Alberto. «Ornament of the World: Urban Change in Early Islamic Qurțuba». En Panzram, Sabine (ed.). The Power of Cities. The Iberian Peninsula from Late Antiquity to the Early Modern Period. Leiden: Brill, 2019, pp. 107-160.

Treadwell, Luke. «Mihrab and 'Anaza' or 'Sacrum and Spear'? A Reconsideration of an Early Marwanid Silver Drachm». Muqarnas, 2005, vol. 22, pp. 1-28.

Walmsley, Alan y Damgaard, Kristoffer. "The Umayyad congregational mosque of Jarash in Jordan and its relationship to early mosques». Antiquity, 2005, vol. 79, n. ${ }^{\circ} 304$, pp. 362-378.

WHELAN, Estelle. "Forgotten witness: Evidence for the early codification of the Qur'àn». The Journal of the American Oriental Society. American Oriental Society, 1998, vol. 118, n. ${ }^{\circ}$, pp. 1-14. 